\title{
The simultaneous calcination/sulfation reaction of limestone under oxy-fuel CFB conditions
}

\author{
Liang Chen ${ }^{1}$, Chunbo Wang ${ }^{1}$, Guangjing Yan $^{1}$, Fan Zhao ${ }^{1}$, Edward J. Anthony ${ }^{2 *}$ \\ ${ }^{1}$ School of Energy and Power Engineering, North China Electric Power University, \\ Baoding 071000, China \\ ${ }^{2}$ School of Power Engineering, Cranfield University, Cranfield, Bedfordshire MK43 \\ 0AL, UK \\ *Corresponding author. E-mail address: b.j.anthony@cranfield.ac.uk
}

\begin{abstract}
Using a customized thermogravimetric analyzer, the characteristics of the simultaneous calcination/sulfation reaction of limestone (the simultaneous reaction) under oxy-fuel circulating fluidized bed (CFB) boiler conditions were investigated. The results were compared with the calcination-then-sulfation reaction (the sequential reaction) that has been widely adopted by previous investigators. The sample mass in the simultaneous reaction was higher than that in the sequential reaction. With the increase of $\mathrm{SO}_{2}$ concentration (0-0.9\%), the mass difference between the two reaction scenarios increased; while with the increase of temperature (890-950 ${ }^{\circ} \mathrm{C}$ ), the difference became smaller. Calcination in the presence of $\mathrm{SO}_{2}$ was slower than that without $\mathrm{SO}_{2}$. With the increase of $\mathrm{SO}_{2}$ concentration, the pore volume of the calcined $\mathrm{CaO}$ decreased, and the effectiveness factors of the calcination reaction also declined. This indicates when $\mathrm{CaSO}_{4}$ forms, the pores in $\mathrm{CaO}$ were filled or blocked thus increasing the internal resistance to $\mathrm{CO}_{2}$. Because the simultaneous process is the real one in CFB boilers, and it shows different characteristics from the sequential reaction, all investigations of $\mathrm{CaO}$ sulfation in $\mathrm{CFB}$ should follow this approach. Also in this work, the effects of $\mathrm{SO}_{2}$ concentration, temperature and $\mathrm{H}_{2} \mathrm{O}$ on the simultaneous reaction were studied. The sulfation ratio in the simultaneous reaction increased with higher $\mathrm{SO}_{2}$ concentration. Compared with that in the absence of $\mathrm{H}_{2} \mathrm{O}, 8 \% \mathrm{H}_{2} \mathrm{O}$ in flue gas significantly improved the sulfation ratio. In the tested range $\left(890-950{ }^{\circ} \mathrm{C}\right)$, the optimum temperature for sulfation was around $890{ }^{\circ} \mathrm{C}$. The sulfation rate in the mass-loss stage was higher than that in the fast sulfation stage, which is likely due to the continuous generation of nascent $\mathrm{CaO}$ in this stage.
\end{abstract}

Keywords: Oxy-fuel; Calcination; Sulfation; Simultaneous reaction; Limestone; CFB

\section{Introduction}

Oxy-fuel combustion is commonly considered to be one of the most promising technologies for $\mathrm{CO}_{2}$ capture from coal-fired boilers [1, 2]. Compared with pulverized coal combustion, oxy-fuel CFB can burn a wider range of fuels and achieve better combustion stability, and hence the technology is receiving increasing attention $[3,4]$. 
In oxy-fuel CFB, limestone is usually used for in-situ capture of $\mathrm{SO}_{2}$. Depending on the fuels, the operating temperature of CFB varies over the range of about $850-950{ }^{\circ} \mathrm{C}$. There are two routes for the $\mathrm{SO}_{2}$ capture reaction. When the furnace temperature is lower than the decomposition temperature of $\mathrm{CaCO}_{3}$, limestone reacts directly with $\mathrm{SO}_{2}[5]$ :

$$
\mathrm{CaCO}_{3}+\mathrm{SO}_{2}+1 / 2 \mathrm{O}_{2} \rightarrow \mathrm{CaSO}_{4}+\mathrm{CO}_{2}
$$

This is known as direct sulfation of limestone. The decomposition temperature, $T(\mathrm{~K})$, of $\mathrm{CaCO}_{3}$ depends on the $\mathrm{CO}_{2}$ particle pressure, $P_{\mathrm{e}}$ (atm.), and can be calculated by [6]

$$
\log P_{\mathrm{e}}=7.079-\frac{8308}{T}
$$

Under typical conditions of $80 \% \mathrm{CO}_{2}$ in oxy-fuel $\mathrm{CFB}$, the $\mathrm{CaCO}_{3}$ decomposition temperature is about $880{ }^{\circ} \mathrm{C}$. However when burning fuels like petroleum coke or anthracite, the furnace temperature is typically over $900{ }^{\circ} \mathrm{C}$. Here the limestone will decompose first and then react with $\mathrm{SO}_{2}$, and this is known as indirect sulfation, and can described by the following global mechanism:

$$
\begin{gathered}
\mathrm{CaCO}_{3} \rightarrow \mathrm{CaO}+\mathrm{CO}_{2} \\
\mathrm{CaO}+\mathrm{SO}_{2}+1 / 2 \mathrm{O}_{2} \rightarrow \mathrm{CaSO}_{4}
\end{gathered}
$$

In recent years, much work [7, 8] has focused on the indirect sulfation of limestone under oxy-fuel conditions. It has been found that the sulfation of $\mathrm{CaO}$ under $\mathrm{CO}_{2} / \mathrm{O}_{2}$ conditions has two reaction stages, a fast sulfation stage and a slow sulfation stage [9]. The research of Obras-Loscertales et al. [7] showed that the fast stage was controlled by $\mathrm{SO}_{2}$ gas diffusion through the pores of the particle, and the slow stage was controlled by the gas diffusion through the $\mathrm{CaSO}_{4}$ product layer.

The sulfation rate of $\mathrm{CaO}$ can be influenced by many factors, such as the particle size, temperature, $\mathrm{SO}_{2}$ concentration, $\mathrm{CO}_{2}$ concentration, and $\mathrm{H}_{2} \mathrm{O}$ concentration. Many investigators [7, 8, 10] have found that the sulfation rate increases with decreased particle size and increased $\mathrm{SO}_{2}$ concentration. According to the research of Diego et al. [10], once calcination occurred, the sulfation performance of limestone is barely affected by the $\mathrm{CO}_{2}$ concentration. Similar results were found by Snow et al. [11] and García-Labiano et al. [8].

Using a small fluidized bed reactor, de Diego et al. $[12,13]$ found that the optimum temperature for sulfur retention working under $65 \% \mathrm{CO}_{2}$ conditions was around 900-925 ${ }^{\circ} \mathrm{C}$. However, the operation experiences of a $30 \mathrm{MW}$ oxy-fuel CFB boiler [14] showed the optimum temperature was around $880-890^{\circ} \mathrm{C}$. García-Labiano et al. [8] found that for indirect sulfation under $60 \% \mathrm{CO}_{2}$ conditions, the sulfation ratio decreased with temperature in the range of $900-975{ }^{\circ} \mathrm{C}$. Thus, $900{ }^{\circ} \mathrm{C}$ should be an appropriate bed temperature for sulfur capture in oxy-fuel CFB.

$\mathrm{H}_{2} \mathrm{O}$ is another factor that influences the reaction characteristics of limestone. Many investigations [15-18] have shown that $\mathrm{H}_{2} \mathrm{O}$ can increase the calcination rate of limestone. The research of Wang et al. [18] suggested that the reason may be that $\mathrm{H}_{2} \mathrm{O}$ can weaken the bonding between $\mathrm{C}-\mathrm{O}$ in $\mathrm{CaCO}_{3}$. Previous investigators [16, 19-21] have found that $\mathrm{H}_{2} \mathrm{O}$ can also enhance the sulfation rate of $\mathrm{CaO}$. Wang et al. [19] reported that $\mathrm{Ca}(\mathrm{OH})_{2}$ may be formed and act as an intermediate in the presence of 
$\mathrm{H}_{2} \mathrm{O}$, while Jiang et al. [21] suggested that $\mathrm{H}_{2} \mathrm{O}$ may enhance the solid state ion diffusion in the $\mathrm{CaSO}_{4}$ layer.

In the above work on indirect sulfation, both the calcined limestone $(\mathrm{CaO})[19,22]$ and the raw limestone $\left(\mathrm{CaCO}_{3}\right)$ [23-25] have been used as sorbents. When calcined limestone was used for $\mathrm{SO}_{2}$ capture, the particles were first calcined in an atmosphere without $\mathrm{SO}_{2}$ to form $\mathrm{CaO}$, then the sulfation of $\mathrm{CaO}$ was examined. This process is can be called the calcination-then-sulfation reaction of limestone (designated as the sequential reaction) [26]. However, when the raw limestone is introduced into a CFB furnace and experiences indirect sulfation, both calcination and sulfation reactions occur simultaneously. This process can be called the simultaneous calcination/sulfation reaction (designated as the simultaneous reaction) [27].

In the simultaneous reaction, calcination and sulfation can affect each other, producing different behavior compared to the sequential reactions. Olas et al. [28] reported that when the limestone particles were calcined in flue gases containing $\mathrm{SO}_{2}$, the sulfation clearly limited the calcination process. Our previous work [26] showed a similar phenomenon. In other work [27], we have found that there was 3-5\% undecomposed $\mathrm{CaCO}_{3}$ in the particles after 90 min of the simultaneous reaction. The investigation of Chen et al. [29] showed that the sulfation rate of limestone was much faster before complete $\mathrm{CaCO}_{3}$ decomposition than after.

Both the simultaneous and the sequential processes have usually been adopted in the investigations of indirect sulfation. But in practical CFB operation, the simultaneous reaction is the true reaction process of limestone [26]. Thus, a basic question is whether the two processes give the same results on sulfation characteristics of limestone. However, there are only limited reports on this topic, especially under oxy-fuel combustion conditions. Obras-Loscertales et al. [7] found that, compared with pre-calcined limestone $(\mathrm{CaO})$, the sulfation conversion of raw limestone was higher. Our previous study [30] also showed that the simultaneous reaction has different characteristics compared with the sulfation of $\mathrm{CaO}$.

In spite decades of studies on limestone sulfation in CFB, there are still many unclear issues, such as the basic reaction mechanism [31], and a full understanding of ways to improve sorbent utilization [5]. This systemic failure to fully explore such systems is in part due to the fact that researchers insist on using idealized systems and investigating simplified reaction processes. Also, many researchers have used commercial thermogravimetric analyzer (TGA) to study the sulfation reaction of $\mathrm{CaO}$. However, because of the long heat-up duration of the commercial TGA, sorbents samples experience physical or chemical change before the sulfation reaction, so a commercial TGA is not the best experimental system to study the sulfation of limestone. In order to accurately understand the sulfation in $\mathrm{CFB}$, the whole reaction process (rather than the sulfation of $\mathrm{CaO}$ ) should be examined under a realistic environment. Thus in our previous work [26, 27, 30], we have investigated the simultaneous calcination/sulfation reaction in air-fuel CFB and found it was quite different from the sulfation of $\mathrm{CaO}$, indicating that the sulfation of $\mathrm{CaO}$ does not reflect the real reaction process of limestone in CFB. We therefore, suggest that researchers in this field pay attention to the simultaneous reaction. 
A constant-temperature TGA (Fig. 1) was used in this work. Compared with the commercial TGA, the constant-temperature TGA employed here is more suitable to study the simultaneous reaction. First, because of the much higher temperature rise rate $\left(>1000{ }^{\circ} \mathrm{C} / \mathrm{s}\right)$ of the constant temperature TGA, the materials started to react instantaneously once the sorbents reached the furnace, similar to the behavior in real CFB boilers, which do not experience the long heat-up stage of the commercial TGA. Second, about $50 \mathrm{mg}$ of materials can be collected in one test, so sufficient materials (about $1 \mathrm{~g}$ ) can be obtained by a dozen repeats for the pore structure analysis of the sorbents; while in commercial TGA (only $10 \mathrm{mg}$ material is produced in each test), so too many (about 100) repetitions are needed to collect the required material.

In this work, the simultaneous reaction under oxy-fuel CFB conditions was investigated. Because of the peculiarity of oxy-fuel combustion (high $\mathrm{CO}_{2} / \mathrm{SO}_{2} / \mathrm{H}_{2} \mathrm{O}$ concentration), the simultaneous reaction under oxy-fuel conditions also shows special characteristics compared with that under air-fuel conditions; therefore, additional investigation is necessary. Using the constant-temperature TGA system, the effects of $\mathrm{SO}_{2}$ concentration, temperature, and $\mathrm{H}_{2} \mathrm{O}$ on the calcination and sulfation characteristics of the simultaneous reaction were studied. The sequential reaction was also examined to explore the differences between the two reaction processes. The test results show that the simultaneous reaction was very different from the sequential reaction under oxy-fuel conditions. To provide a deeper explanation of the differences, the pore structures of the sorbents were also measured. The findings in this work provide a new understanding of the real sulfation process of limestone in oxy-fuel CFB boilers.

\section{Experiments}

\subsection{Materials and experimental}

Two kinds of typical limestone, Baoding and Xinxiang, were used for the tests. The limestones were milled and sieved to a narrow particle size range $(0.4-0.45 \mathrm{~mm})$. Their chemical composition is given in Table 1.

Table 1. Limestone composition.

\begin{tabular}{llllllllllll}
\hline $\begin{array}{l}\text { Compound } \\
\text { (wt\%) }\end{array}$ & $\mathrm{SiO}_{2}$ & $\mathrm{Al}_{2} \mathrm{O}_{3}$ & $\mathrm{Fe}_{2} \mathrm{O}_{3}$ & $\mathrm{TiO}_{2}$ & $\mathrm{P}_{2} \mathrm{O}_{5}$ & $\mathrm{CaO}$ & $\mathrm{MgO}$ & $\mathrm{SO}_{3}$ & $\mathrm{Na}_{2} \mathrm{O}$ & $\mathrm{K}_{2} \mathrm{O}$ & $\begin{array}{c}\text { Loss on } \\
\text { Fusion }\end{array}$ \\
\hline Baoding & 0.67 & 0.78 & $<0.10$ & $<0.05$ & $<0.03$ & 54.93 & $<0.10$ & $<0.10$ & $<0.10$ & $<0.10$ & 42.90 \\
Xinxiang & 0.45 & 0.56 & 0.15 & 0.05 & $<0.03$ & 55.02 & 0.48 & $<0.10$ & $<0.20$ & 0.24 & 42.78 \\
\hline
\end{tabular}

The experimental system is shown in Fig. 1. The main reactor is an electrical tube furnace ( $800 \mathrm{~mm}$ long, $40 \mathrm{~mm}$ inner diameter). Synthetic flue gas was composed of mixed gases $\left(\mathrm{CO}_{2}, \mathrm{SO}_{2}, \mathrm{O}_{2}, \mathrm{~N}_{2}\right.$ and $\left.\mathrm{H}_{2} \mathrm{O}\right)$. The $\mathrm{H}_{2} \mathrm{O}$ was generated by the evaporation of water injected into a heated tube $\left(200{ }^{\circ} \mathrm{C}\right)$, and its flow was controlled by an injection pump. Other gases were from gas cylinders and their flow rates were controlled by flowmeters. The validation of the stabilization and repeatability of the present system is also provided in Supporting Information, and our previous work [16, $26,32]$ also demonstrates that this system has sufficient accuracy for this type of study. 


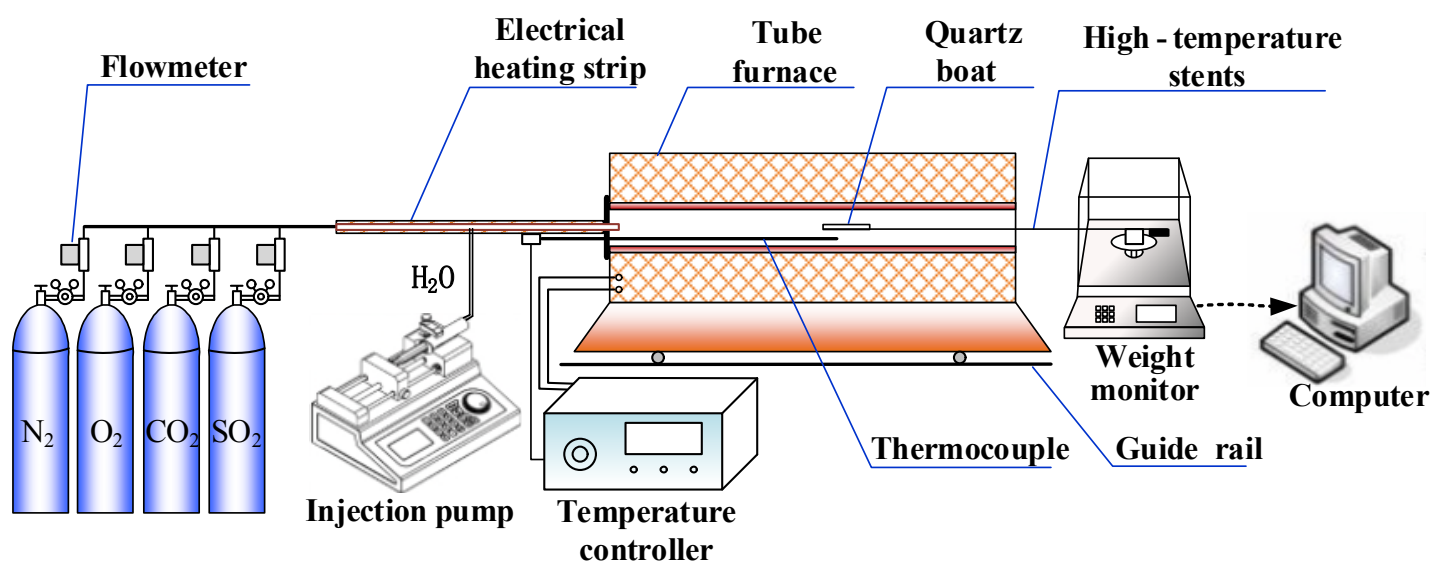

Fig. 1. The experimental system (constant-temperature TGA).

When the tube furnace reached the set temperature, the synthetic flue gas was passed through it for 15 min before the test was started. A gas flow of $1.2 \mathrm{dm}^{3} / \mathrm{min}$ was used for all tests. This flow rate is high enough to eliminate the external gas diffusion resistance as determined by the preliminary experiments (see Supporting Information).

In the simultaneous reaction tests, limestone sample $(80 \mathrm{mg})$ was loaded in the quartz boat (100 mm long, $10 \mathrm{~mm}$ wide) and moved into the furnace to react. The mass of the sample during reaction was recorded continuously for $90 \mathrm{~min}$ by the weight monitor (accuracy $\pm 0.1 \mathrm{mg}$ ). While for the sequential reaction, the limestone sample was first calcined in an atmosphere without $\mathrm{SO}_{2}\left(70 \% \mathrm{CO}_{2}, 0\right.$ or $8 \% \mathrm{H}_{2} \mathrm{O}, \mathrm{N}_{2}$ as balance). Once the limestone sample decomposed completely to $\mathrm{CaO}$, which can be easily detected by the mass change of the sample, it was moved out of the furnace and collected before being subjected to the sulfation reaction.

Each test was carried out in triplicate or more to assure repeatability, and in all tests the standard deviations of the calcination and sulfation ratios were less than $1 \%$. Table 2 summarizes the experimental conditions.

Table 2. Experimental conditions.

\begin{tabular}{ll}
\hline Conditions & Value \\
\hline Temperature $\left({ }^{\circ} \mathrm{C}\right)$ & $890,900,925,950$ \\
$\mathrm{CO}_{2}$ concentration $(\%)$ & 70 \\
$\mathrm{O}_{2}$ concentration $(\%)$ & 5 \\
$\mathrm{SO}_{2}$ concentration $(\%)$ & $0,0.3,0.6,0.9$ \\
$\mathrm{H}_{2} \mathrm{O}$ concentration $(\%)$ & 0,8 \\
$\mathrm{~N}_{2}$ concentration $(\%)$ & Balance \\
Particle size $(\mathrm{mm})$ & $0.4-0.45$ \\
\hline
\end{tabular}

\subsection{Data analysis}

When limestone is calcined and sulfated simultaneously, the calcination ratio cannot be calculated directly from the mass data. To determine the calcination ratio, the sample at a given reaction time was removed quickly from the furnace into a glass tube purged by $\mathrm{N}_{2}$, and cooled down. Then the sample was weighed, crushed and calcined again in pure $\mathrm{N}_{2}$, until the sample was totally calcined. It has been confirmed that $\mathrm{CO}_{2}$ or $\mathrm{H}_{2} \mathrm{O}$ absorbed by the sample in the moving, cooling, weighing and 
crushing process is negligible (see Supporting Information). The calcination ratio of the sample was calculated by:

$$
X_{C}=1-\frac{m_{t}}{\gamma m_{0}} \frac{m_{1}-m_{2}}{m_{1}} \frac{M_{\mathrm{CaCO}_{3}}}{M_{\mathrm{CO}_{2}}}
$$

where $m_{0}$ is the initial sample mass; $m_{t}$ is the sample mass after a given reaction duration; $m_{1}$ is the mass of sample after crushing; $m_{2}$ is the mass of the sample after being totally calcined; $\gamma$ is the $\mathrm{CaCO}_{3}$ mass ratio of limestone; and $M_{\mathrm{CaCO}_{3}}$ and $M_{\mathrm{CO}_{2}}$ are the mole mass of $\mathrm{CaCO}_{3}$ and $\mathrm{CO}_{2}$, respectively.

The sulfation ratio of the limestone samples can be calculated by the following expression:

$$
X_{S}=\frac{\frac{m_{t}}{\eta m_{0}}\left(1-\frac{x_{t} M_{\mathrm{CO}_{2}}}{M_{\mathrm{CaCO}_{3}}}\right)+\frac{M_{\mathrm{CO}_{2}}}{M_{\mathrm{CaCO}_{3}}}-\frac{1}{\gamma}}{\left(M_{\mathrm{CaSO}_{4}}-M_{\mathrm{CaO}}\right) / M_{\mathrm{CaCO}_{3}}}
$$

where $x_{\mathrm{t}}$ is the mass ratio of the undecomposed $\mathrm{CaCO}_{3}$ in the sample; and $M_{\mathrm{CaO}}$ and $\mathrm{M}_{\mathrm{CaSO}_{4}}$ are the molecular mass of $\mathrm{CaO}$ and $\mathrm{CaSO}_{4}$, respectively.

All the sample mass curves in the following figures were normalized to provide an initial sample mass of one unit (the normalized mass equals the sample mass divided by its initial mass).

\section{Results and Discussion}

\subsection{Simultaneous reaction under different $\mathrm{SO}_{2}$ concentrations}

\subsubsection{The reaction kinetics}

First, the differences between the simultaneous reaction and the sequential reaction were investigated. Three $\mathrm{SO}_{2}$ concentrations $(0.3 \%, 0.6 \%, 0.9 \%)$ were chosen for the tests. Here, Baoding limestone was used. All tests were carried out at $900^{\circ} \mathrm{C}$ and without steam. The sample masses in the two reaction patterns are compared in Fig. 2.

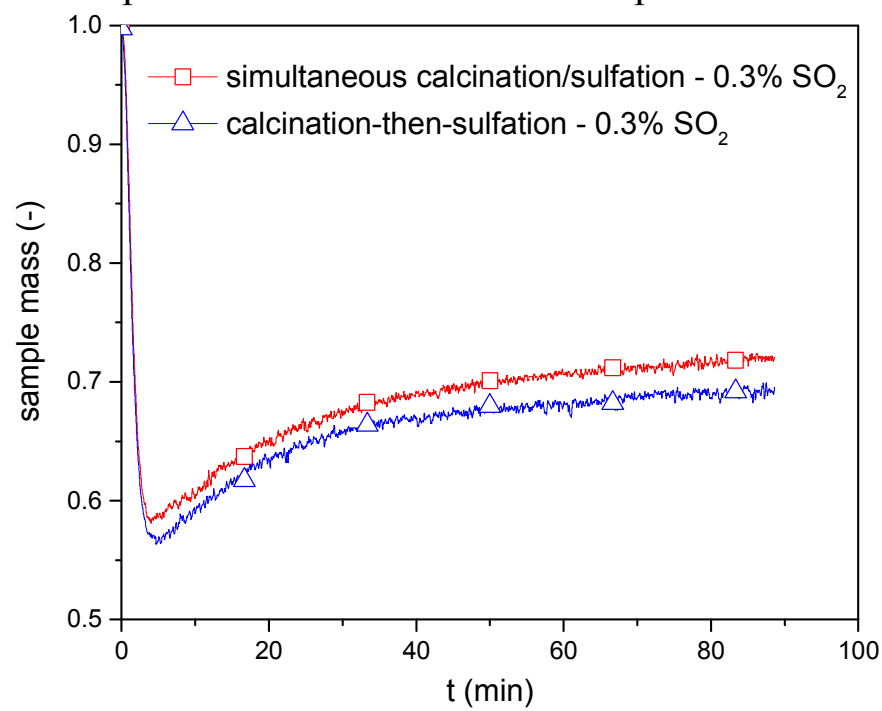

(a) 


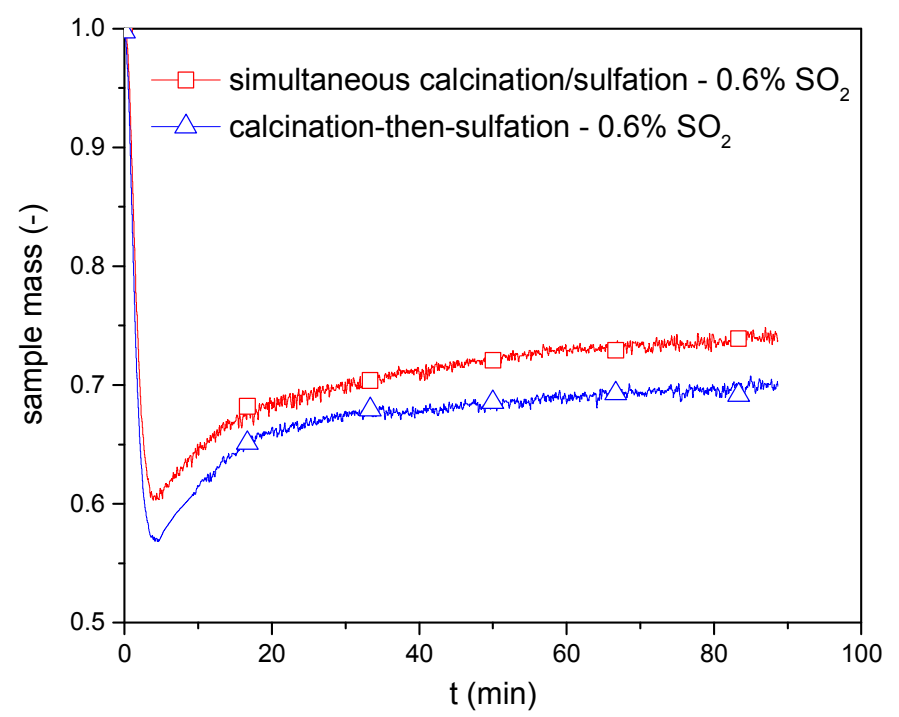

(b)

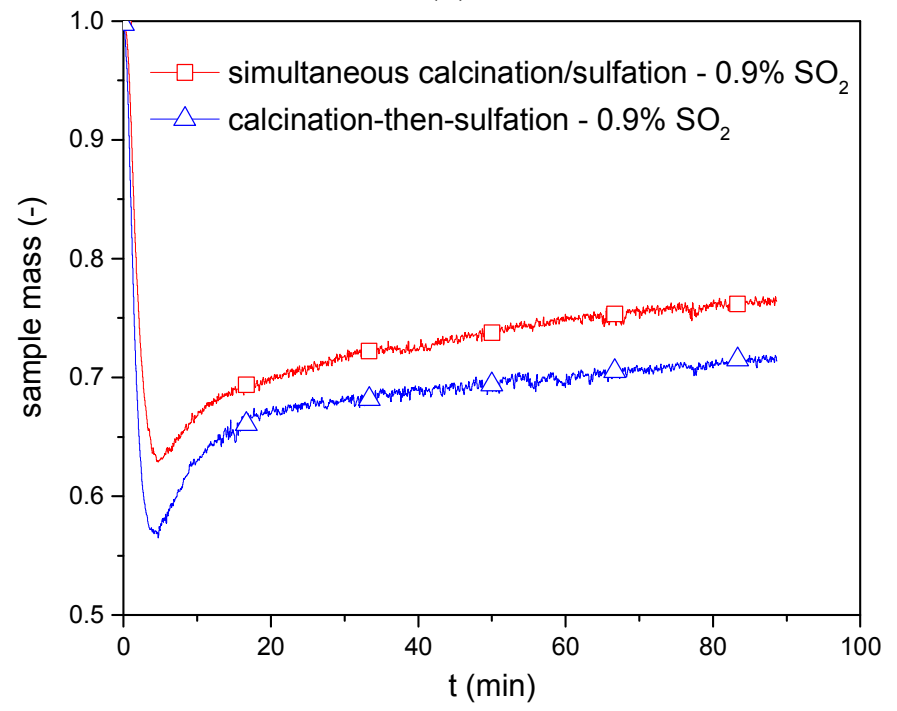

(c)

Fig. 2. Sample mass in simultaneous reaction and sequential reaction under different $\mathrm{SO}_{2}$ concentrations. (a) $0.3 \% \mathrm{SO}_{2}$; (b) $0.6 \% \mathrm{SO}_{2}$; and (c) $0.9 \% \mathrm{SO}_{2}$.

As shown in Fig. 2, there are some similarities in the change of the sample mass under different $\mathrm{SO}_{2}$ concentrations. Under each concentration of $\mathrm{SO}_{2}$, the sample mass declined first then rose for both the simultaneous and sequential reactions. There was a minimum mass point for each curve, dividing the curve into two stages, the mass-loss stage and the mass-growth stage. For the sequential reaction, the minimum mass point is the end of the calcination reaction and the beginning of the sulfation reaction. But for the simultaneous reaction, it is the point when the mass-loss rate caused by calcination reaction equals the mass-growth rate caused by the sulfation reaction [27].

The mass-growth stage, dominated by the sulfation reaction, can be divided into two stages as well, the fast sulfation stage and the slow sulfation stage. Taking conditions of $0.6 \% \mathrm{SO}_{2}$ for example, the mass-growth rate of samples from the minimum mass points to $20 \mathrm{~min}$ was much faster than that after $20 \mathrm{~min}$. Therefore, the stage from the minimum mass point to 20 min was designated as the fast sulfation 
stage, and the stage after 20 min was designated as the slow sulfation stage. Note that the dividing line is not strict, but serves to enhance discussion of these processes.

In Fig. 2, the sample mass of the simultaneous reaction was always higher than that of the sequential reaction. Taking a condition of $0.6 \% \mathrm{SO}_{2}$ for example, the minimum mass and final mass $(90 \mathrm{~min}$ ) of the simultaneous reaction are $6.9 \%$ and $5.3 \%$ higher, respectively than those of the sequential reaction. Under the other two concentrations of $\mathrm{SO}_{2}$, similar phenomena can be found.

With the increase of $\mathrm{SO}_{2}$ concentration $(0.3 \%$ to $0.9 \%)$, the difference of the sample minimum mass and final mass between the two reaction patterns increased. After 90 min of reaction, the final samples under all conditions were crushed and calcined in $\mathrm{N}_{2}$. No further mass loss was found, so the sulfation ratios of the final samples were determined by formula (6) with $x_{\mathrm{t}}=0$, and the results are shown in Fig. 3.

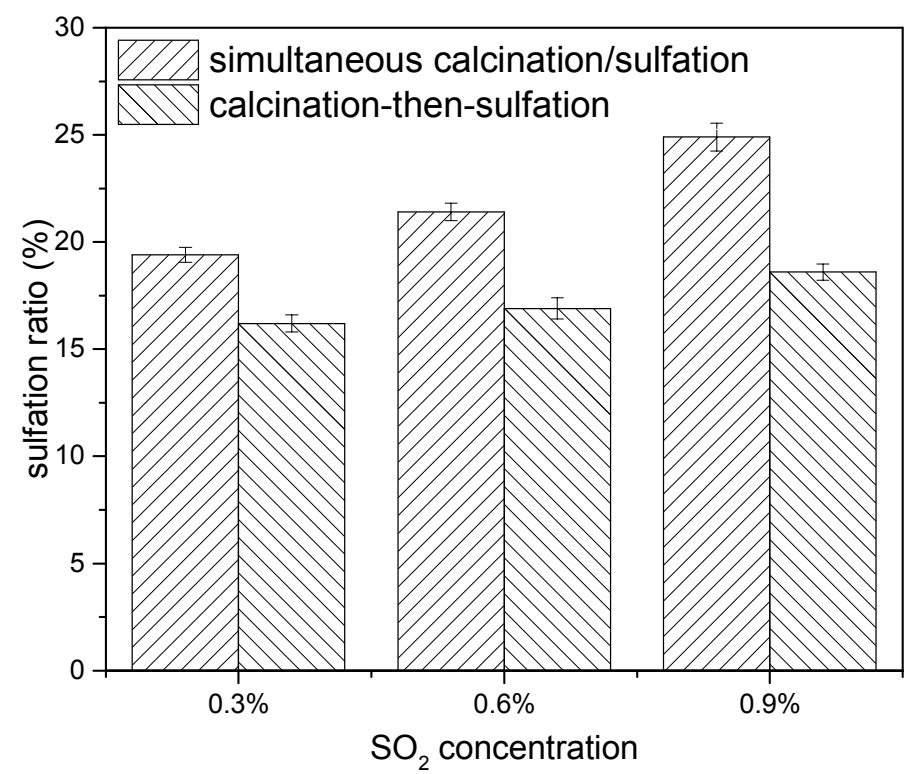

Fig. 3. The sulfation ratios of the final samples under different $\mathrm{SO}_{2}$ concentrations.

Fig. 3 shows that the sulfation ratio of the final sample of the simultaneous reaction is higher than that of the sequential reaction under each $\mathrm{SO}_{2}$ concentration. The difference of the sulfation ratio between the two reaction patterns increased at higher $\mathrm{SO}_{2}$ concentration, from $19.8 \%$ (relative difference) at $0.3 \% \mathrm{SO}_{2}$ to $33.9 \%$ at $0.9 \%$ $\mathrm{SO}_{2}$. The difference between the two reaction patterns is due mainly to the different calcination process. To understand this difference, the mass-loss stages of the samples under different $\mathrm{SO}_{2}$ concentrations were compared in Fig. 4(a).. The sulfation and calcination ratios in this stage were also measured, Fig. 4(b) and (c). 


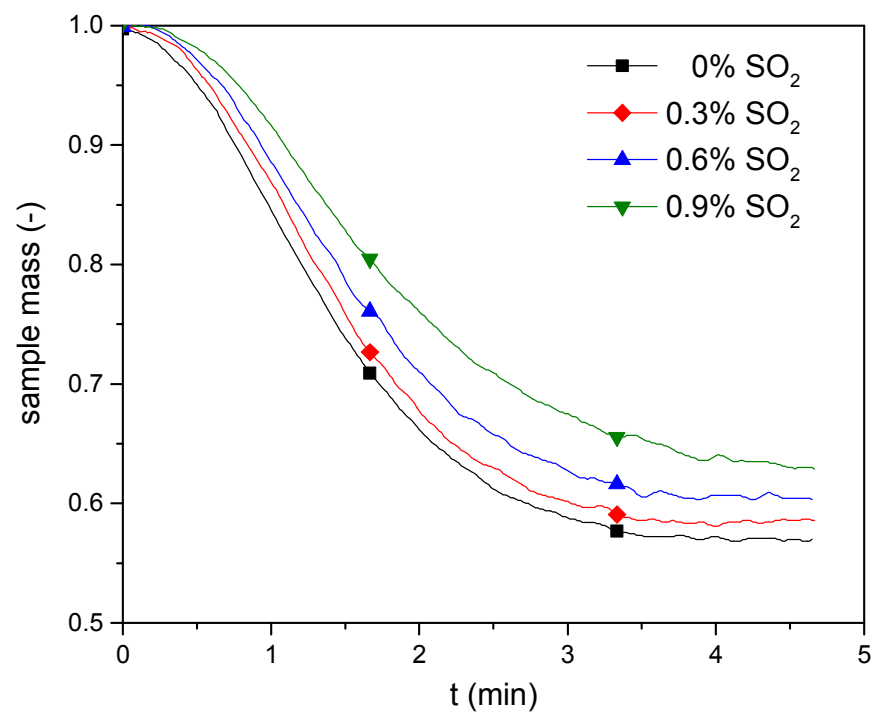

(a)

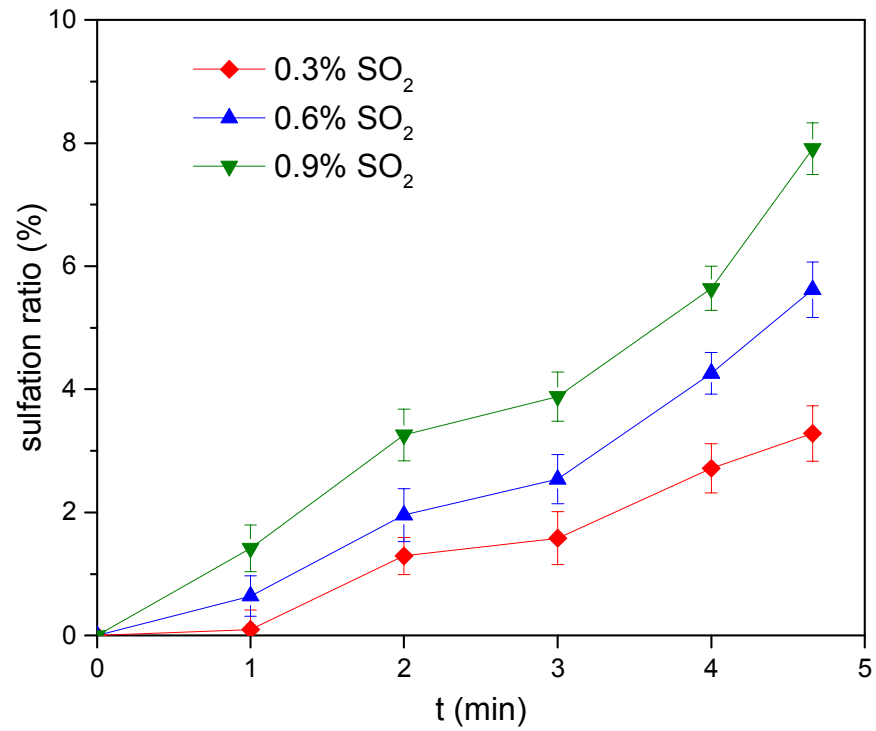

(b)

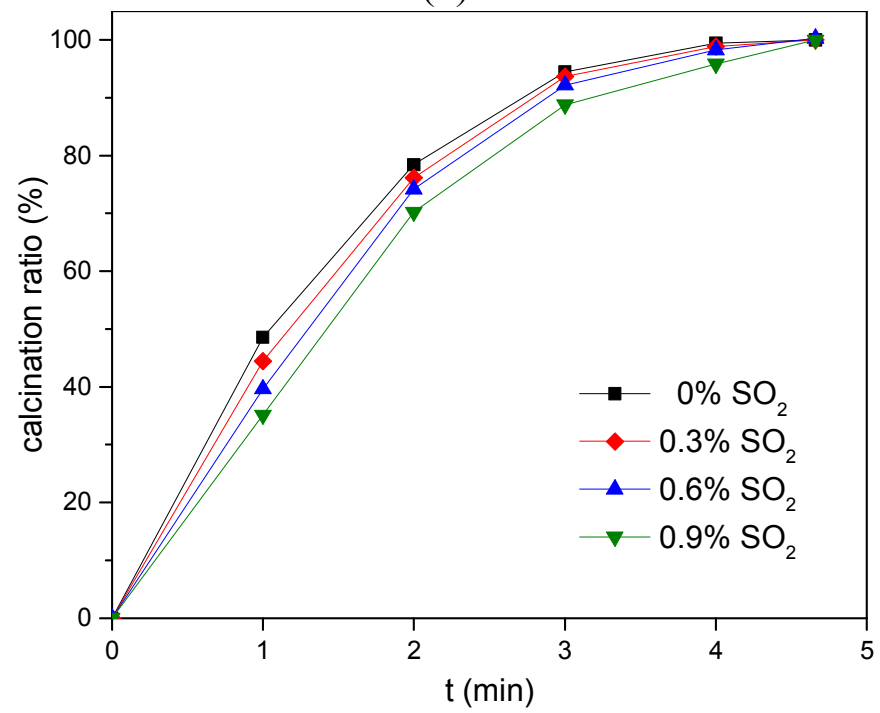

(c) 
Fig. 4. The mass-loss stage under different $\mathrm{SO}_{2}$ concentrations. (a) the sample mass; (b) the sulfation ratio; and (c) the calcination ratio.

As shown in Fig. 4(a), the sample mass resulting from calcination without $\mathrm{SO}_{2}$ is the lowest. When $\mathrm{SO}_{2}$ concentration increased, the mass-loss rate decreased and the minimum mass was higher. When limestone was calcined with $\mathrm{SO}_{2}$, the calcination and sulfation reactions occurred simultaneously, and the change in sample mass is the overall result of the released $\mathrm{CO}_{2}$ and the captured $\mathrm{SO}_{2}$. Compared with the calcination without $\mathrm{SO}_{2}$, the higher sample mass of the calcination with $\mathrm{SO}_{2}$ may be arise in two ways: mass gain from the captured $\mathrm{SO}_{2}$; and a slower calcination reaction caused by the formed $\mathrm{CaSO}_{4}$. To demonstrate the validity of this explanation, the sulfation and calcination ratios in this stage were examined, as shown in Fig. 4(b) and (c).

When $\mathrm{SO}_{2}$ was present in the calcination atmosphere, $\mathrm{CaSO}_{4}$ formed and accumulated during the calcination process. With the increase of $\mathrm{SO}_{2}$ concentration, the sulfation ratio increased faster (Fig. 4(b)), which means more $\mathrm{CaSO}_{4}$ is formed in this stage. At the same time, the calcination reaction was slowed in the presence of $\mathrm{SO}_{2}$ (Fig. 4(c)), and with higher $\mathrm{SO}_{2}$ concentration, the calcination rate declined still further. This indicated that the decreased mass-loss rate of limestone calcined in the presence of $\mathrm{SO}_{2}$ can be due to the accumulation of $\mathrm{CaSO}_{4}$ and the slowed calcination rate, as described above.

3.1.2. The pore structure and diffusion resistance of $\mathrm{CO}_{2}$

The decreased calcination rate in the presence of $\mathrm{SO}_{2}$ is attributed to the formation of $\mathrm{CaSO}_{4}$. A possible explanation was put forward in our previous work [26] is that the calcination of limestone particles usually occurred from the particle surface and proceeds inwards. When a $\mathrm{CaO}$ layer is formed, the pores in it serve as the pathway for the diffusion of $\mathrm{CO}_{2}$, but in the presence of $\mathrm{SO}_{2}$, the sulfation reaction occurred, and $\mathrm{CaSO}_{4}$ formed in the pores of the $\mathrm{CaO}$ layer. This $\mathrm{CaSO}_{4}$ can fill or block the pores in $\mathrm{CaO}$, increase the $\mathrm{CO}_{2}$ diffusion resistance and also the $\mathrm{CO}_{2}$ concentration at the calcination site, consequently decreasing calcination of the $\mathrm{CaCO}_{3}$.

To further demonstrate the validity of this explanation, samples with the same calcination time $\left(4.7 \mathrm{~min}\right.$ ) under different $\mathrm{SO}_{2}$ concentrations were collected and their pore structures were measured by the $\mathrm{N}_{2}$ adsorption method. Their specific surface area and pore volume are shown in Table 3, and the pore size distributions are compared in Fig. 5.

Table 3. Surface area and pore volume of samples under different $\mathrm{SO}_{2}$ concentrations.

\begin{tabular}{lll}
\hline $\mathrm{SO}_{2}(\%)$ & surface area $\left(\mathrm{m}^{2} / \mathrm{g}\right)$ & pore volume $\left(\mathrm{cm}^{3} / \mathrm{g}\right)$ \\
\hline 0 & 11.27 & 0.1285 \\
0.3 & 10.45 & 0.1072 \\
0.6 & 10.04 & 0.0665 \\
0.9 & 9.22 & 0.0335 \\
\hline
\end{tabular}




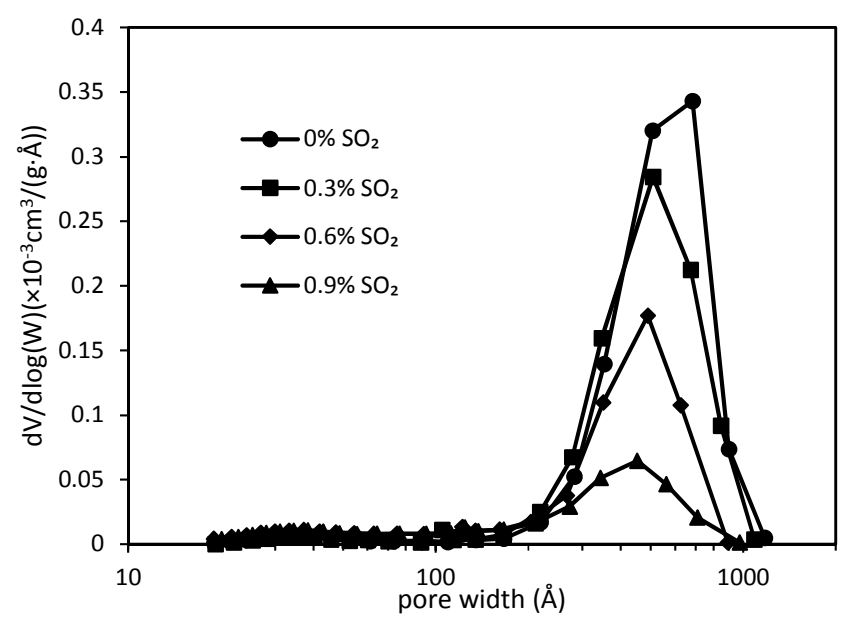

Fig. 5. Pore size distribution of samples under different $\mathrm{SO}_{2}$ concentrations.

As shown in Table 3, with the $\mathrm{SO}_{2}$ concentration increased in the range of $0-0.9 \%$, both the specific surface area and pore volume of samples decreased. Compared with the condition without $\mathrm{SO}_{2}$, the specific surface area and pore volume in $0.9 \% \mathrm{SO}_{2}$ decreased by $18.2 \%$ and $73.9 \%$, respectively. The pore size distribution (Fig. 5) also declined significantly at higher $\mathrm{SO}_{2}$ concentrations. Under conditions of $0-0.9 \% \mathrm{SO}_{2}$, samples with calcination time of 4.7 min decomposed completely, as shown in Fig. 4(c). Therefore, the differences in pore structure in different $\mathrm{SO}_{2}$ concentrations should be attributed to the $\mathrm{CaSO}_{4}$ formed in the pores. The results in Table 3 and Fig. 5 indicate that some pores were filled or blocked by the formed $\mathrm{CaSO}_{4}$. Pore occlusion increases the diffusion resistance of $\mathrm{CO}_{2}$ in the $\mathrm{CaO}$ layer, and decreases calcination of $\mathrm{CaCO}_{3}$ interior, as suggested above.

To quantify the effect of $\mathrm{CaSO}_{4}$ on the calcination rate, the effectiveness factors of the calcination reaction under different $\mathrm{SO}_{2}$ concentrations were calculated. The effectiveness factor for a spherical particle can be calculated by [33]

$$
\eta=\frac{3}{\phi}\left[\operatorname{coth}(\phi)-\frac{1}{\phi}\right]
$$

in which

$$
\phi=R \sqrt{k_{\mathrm{v}} / D_{\mathrm{e}}}
$$

here $R$ is the radius of the particle, $\mathrm{m} ; k_{\mathrm{v}}$ is the reaction rate constant per unit volume, $1 / \mathrm{s} ; D_{\mathrm{e}}$ is the effective diffusion coefficient of $\mathrm{CO}_{2}, \mathrm{~m}^{2} / \mathrm{s}$. The $k_{\mathrm{v}}$ can be calculated from the calcination rate equation

$$
r_{c}=k_{v}\left(C_{\mathrm{CO}_{2}}^{\mathrm{e}}-C_{\mathrm{CO}_{2}}\right)
$$

here $r_{\mathrm{c}}$ is the calcination rate per unit volume limestone particles, $\mathrm{mol} /\left(\mathrm{m}^{3} \cdot \mathrm{s}\right) ; C_{\mathrm{CO}_{2}}^{\mathrm{e}}$ is the equilibrium concentration of $\mathrm{CO}_{2}$ for the calcination of $\mathrm{CaCO}_{3}, \mathrm{~mol} / \mathrm{m}^{3}$, which can be calculated by

$$
C_{\mathrm{CO}_{2}}^{\mathrm{e}}=\frac{101325 P_{\mathrm{e}}}{R_{\mathrm{g}} T}
$$


where $R_{\mathrm{g}}=8.314 \mathrm{~J} /(\mathrm{k} \cdot \mathrm{mol})$.

The $C_{\mathrm{CO}_{2}}$ in formula (9) is the $\mathrm{CO}_{2}$ concentration at the calcination site of the particle, $\mathrm{mol} / \mathrm{m}^{3}$. In the initial calcination stage, the diffusion resistance of $\mathrm{CO}_{2}$ from the calcination site to the outside of the particle should be negligible, so the $C_{\mathrm{CO}_{2}}$ equals to the $\mathrm{CO}_{2}$ concentration in the bulk flue gas. Thus, the $k_{\mathrm{v}}$ in formula (9) can be calculated based on the initial calcination rate under no $\mathrm{SO}_{2}$ condition in Fig. 4(c) and the $\mathrm{CO}_{2}$ concentration in the bulk flus gas.

The effective diffusion coefficient $D_{\mathrm{e}}$ can be calculated by [34]

$$
D_{\mathrm{e}}=D_{\mathrm{A}} \varepsilon^{2}
$$

in which $\varepsilon$ is porosity of the particle; and $D_{\mathrm{A}}$ is the diffusion coefficient of $\mathrm{CO}_{2}$ in pore, $\mathrm{m}^{2} / \mathrm{s}$. $D_{\mathrm{A}}$ includes two patterns of diffusion, molecular diffusion coefficient $D_{\mathrm{AB}}$ and Knudsen diffusion coefficient $D_{\mathrm{k}}$ :

$$
\frac{1}{D_{\mathrm{A}}}=\frac{1}{D_{\mathrm{AB}}}+\frac{1}{D_{\mathrm{k}}}
$$

The $D_{A B}$ can be calculated by Fuller's formula [35]

$$
D_{\mathrm{AB}}=\frac{1 \times 10^{-3} T^{1.75}\left(1 / M_{\mathrm{N}_{2}}+1 / M_{\mathrm{CO}_{2}}\right)^{0.5}}{p\left[\left(\sum v_{i}\right)_{\mathrm{N}_{2}}^{1 / 3}+\left(\sum v_{i}\right)_{\mathrm{CO}_{2}}{ }^{1 / 3}\right]^{2}}
$$

in which $M_{\mathrm{N}_{2}}, M_{\mathrm{CO}_{2}}$ are the molar masses of $\mathrm{N}_{2}$ and $\mathrm{CO}_{2}$, respectively, $\mathrm{g} / \mathrm{mol} ; p$ is the total gas pressure, $1 \mathrm{~atm} ;\left(\sum v_{i}\right)_{\mathrm{N}_{2}}=17.9$ and $\left(\sum v_{i}\right)_{\mathrm{CO}_{2}}=26.9$, are diffusion volumes of $\mathrm{N}_{2}$ and $\mathrm{CO}_{2}$, respectively [35]. At $900^{\circ} \mathrm{C}, D_{\mathrm{AB}}=1.81 \mathrm{~cm}^{2} / \mathrm{s}$.

The Knudsen diffusion coefficient can be calculated by

$$
D_{\mathrm{k}}=\frac{97 \bar{d}}{2} \sqrt{\frac{T}{M_{\mathrm{CO}_{2}}}}
$$

where $\bar{d}$ is average pore diameter, $\mathrm{m}$. Assuming the pore is cylindrical, the average pore diameter can be calculated by:

$$
\bar{d}=\frac{4 V}{S}
$$

where $V$ is the pore volume, $\mathrm{m}^{3} / \mathrm{g}$, and $S$ is the pore surface area, $\mathrm{m}^{2} / \mathrm{g}$, which were shown in Table 3.

The effectiveness factors $\eta$ of the calcination under different $\mathrm{SO}_{2}$ concentrations were calculated and shown in Fig. 6. 


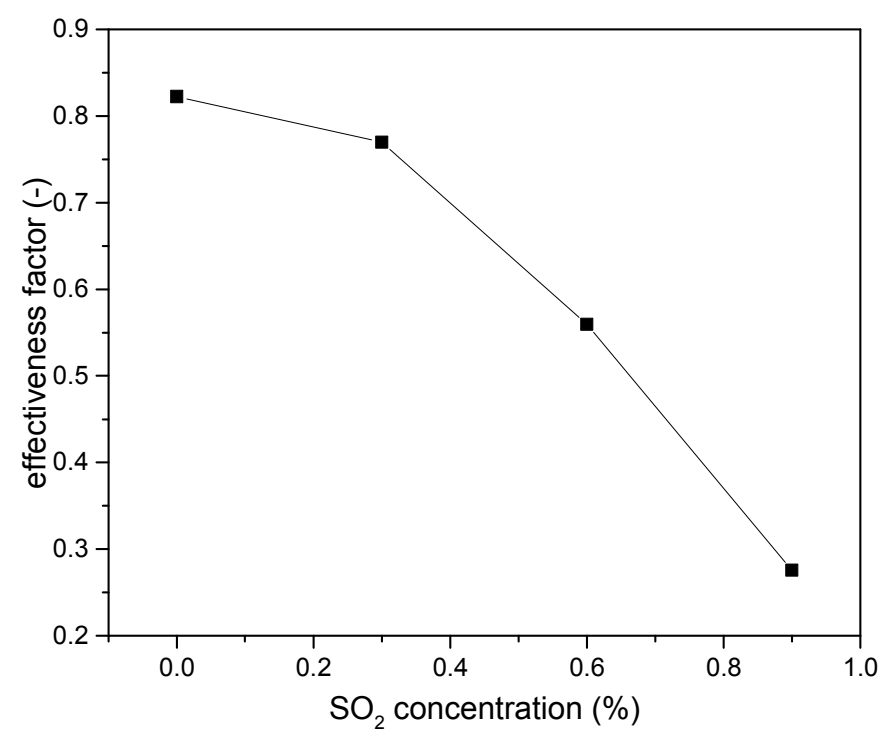

Fig. 6. The effectiveness factors of the calcination reaction

From Fig.6, the effectiveness factors of the calcination reaction decreased with the increasing $\mathrm{SO}_{2}$ concentration, from 0.82 under no $\mathrm{SO}_{2}$ condition to 0.28 under $0.9 \%$ $\mathrm{SO}_{2}$ condition. An effectiveness factor as high as 0.82 means that the calcination reaction was controlled by the chemical reaction rate, while an effectiveness factor as low as 0.28 means that the calcination was controlled by the internal diffusion rate of $\mathrm{CO}_{2}$ [33]. It should be noted that the effectiveness factors were based on the pore structures around the end of the calcination reaction $(4.7 \mathrm{~min})$. So the decrease of $\eta$ in Fig. 6 shows that around the end of the reaction, the calcination controlling step shifted from chemical reaction rate under no $\mathrm{SO}_{2}$ condition to internal diffusion under $0.9 \% \mathrm{SO}_{2}$. The accumulation of $\mathrm{CaSO}_{4}$ in pore is the main reason for the shift.

3.1.3. The effect of $\mathrm{SO}_{2}$ concentration on the simultaneous reaction

In conclusion, both the calcination and sulfation reactions of the simultaneous reaction were different from those of the sequential reaction and, in studies on the reaction of limestone in $\mathrm{CFB}$, the simultaneous reaction process should be followed, rather than the direct sulfation of $\mathrm{CaO}$. In Fig. 7, the sample masses from the simultaneous reaction at different $\mathrm{SO}_{2}$ concentrations $(0.3 \%, 0.6 \%, 0.9 \%)$ were compared. 


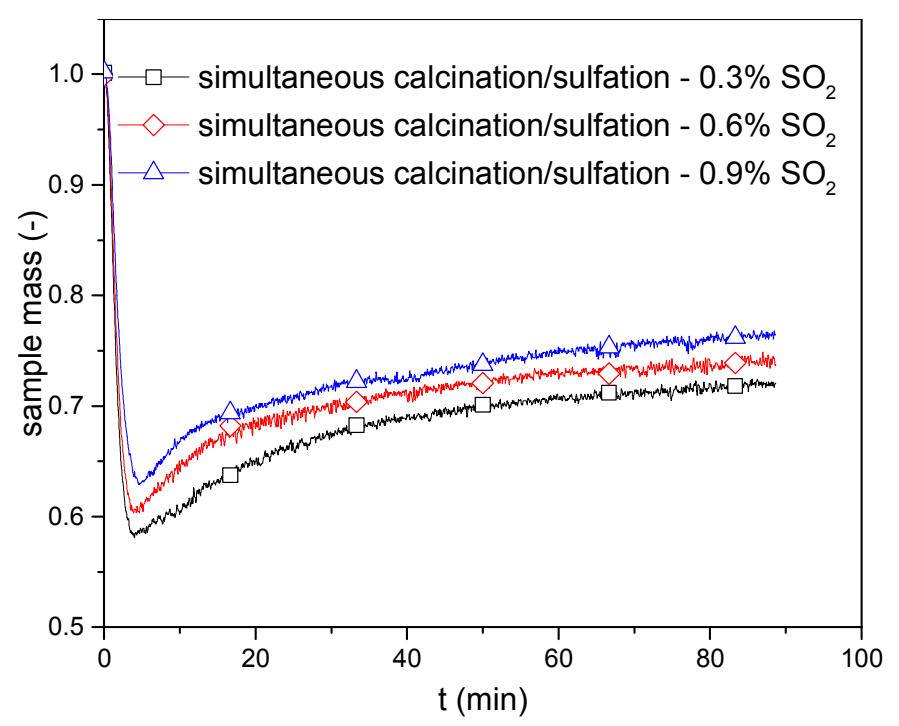

Fig. 7. Influence of $\mathrm{SO}_{2}$ concentration on the simultaneous reaction.

As shown in Fig. 7, with the increase of $\mathrm{SO}_{2}$ concentration, the sample mass was higher in the mass-growth stage. Since the calcination was complete at 4.7 min under each tested condition (Fig. 4(c)), the higher sample mass after this point reflects a higher sulfation degree. This is also reflected in the sulfation ratio of the final samples (Fig. 3), where the sulfation ratio increased with $\mathrm{SO}_{2}$ concentration.

In Fig. 7, it is obvious that the sulfation rate in the fast sulfation stage is faster than that in the slow sulfation stage under each $\mathrm{SO}_{2}$ concentration. But the sulfation rates in the mass-loss stage and the fast sulfation stage cannot be compared directly. To better understand the sulfation characteristics, the average sulfation rates, $r$, in these two stages were compared. The sulfation rate was calculated by

$$
r=\frac{X_{s, 2}-X_{s, 1}}{t_{\mathrm{m}}}
$$

where $t_{\mathrm{m}}$ is the time to reach the minimum mass point, $\mathrm{s}$; when calculating the average sulfation rate in the mass-loss stage, $X_{\mathrm{s}, 1}=0$, and $X_{\mathrm{s}, 2}$ is the sulfation ratio at $t_{\mathrm{m}}$; but when calculating the sulfation rate in the fast sulfation stage, $X_{\mathrm{s}, 1}$ and $X_{\mathrm{s}, 2}$ are the sulfation ratio at $t_{\mathrm{m}}$ and $2 t_{\mathrm{m}}$, respectively, thus $r$ is an average sulfation rate at the beginning of the fast sulfation stage. The average sulfation rates for these two stages are compared in Fig. 8. 


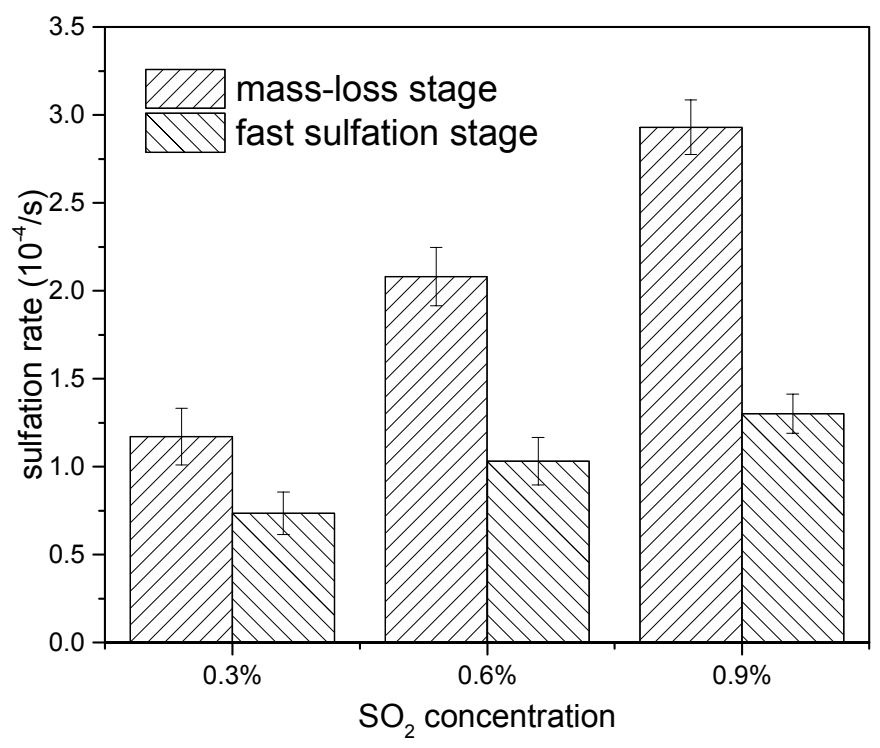

Fig. 8. Sulfation rate in mass-loss stage and fast sulfation stage of the simultaneous reaction.

As shown in Fig. 8, the sulfation rate in both stages increased with $\mathrm{SO}_{2}$ concentration and the difference of the sulfation rate between these two stages also increased. The sulfation rate in the mass-loss stage was higher than that in the fast sulfation stage. For example at $0.6 \% \mathrm{SO}_{2}$, the sulfation rate in the mass-loss stage was about double that in the fast sulfation stage. Similar phenomena were also reported by Chen et al. [29]. Here, in the mass-loss stage, the calcination reaction continued generating nascent $\mathrm{CaO}$ which has a high surface area and porosity. This provides ample reaction sites for the sulfation reaction, leading to the highest sulfation rate in this stage. But in the fast sulfation stage, the calcination rate was slower, or stopped altogether, thus no more nascent $\mathrm{CaO}$ formed. With more $\mathrm{CaSO}_{4}$ accumulating, the available reaction surface decreased and the $\mathrm{SO}_{2}$ diffusion resistance increased, resulting in a slower sulfation rate.

\subsection{Effect of temperature on the simultaneous reaction}

To test the differences between the two reaction patterns at other temperatures, the reactions were examined at $890,900,925$ and $950{ }^{\circ} \mathrm{C}$. All tests were conducted under $0.6 \% \mathrm{SO}_{2}$ without steam on Baoding limestone. Sample masses are shown in Fig. 9.

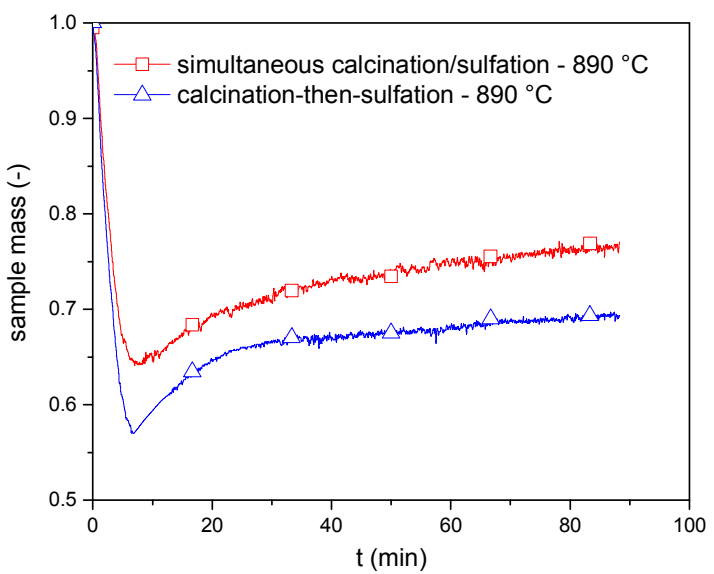

(a)

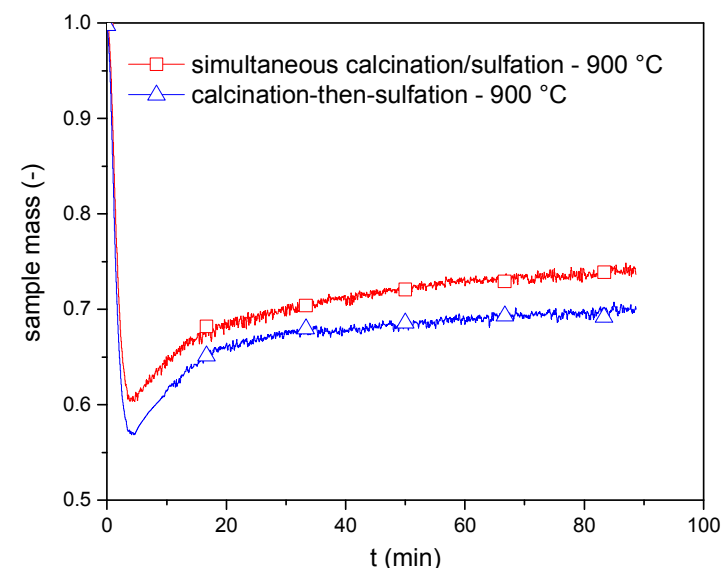

(b) 


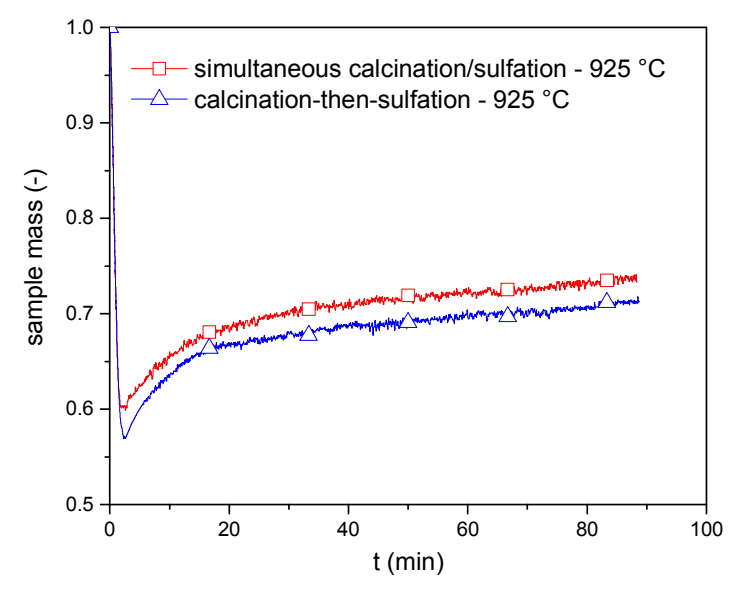

(c)

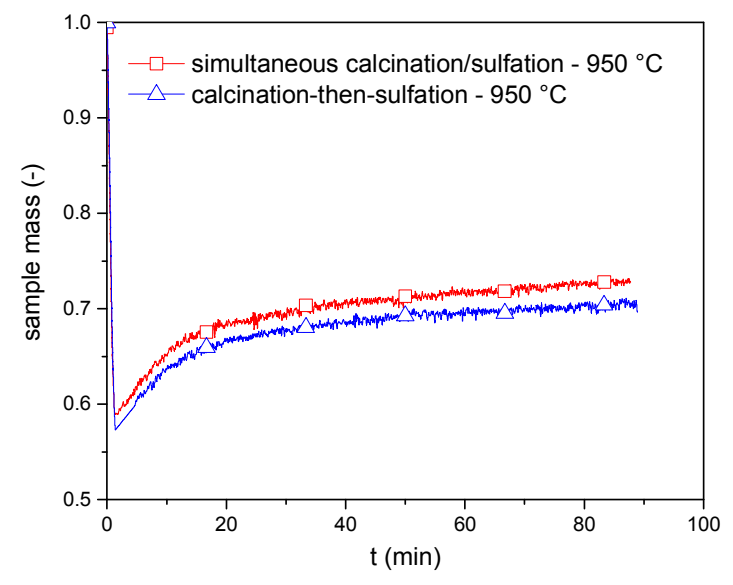

(d)

Fig. 9. Sample masses of the simultaneous and the sequential reactions under different temperatures. (a) $890{ }^{\circ} \mathrm{C}$; (b) $900{ }^{\circ} \mathrm{C}$; (c) $925^{\circ} \mathrm{C}$; and (d) $950{ }^{\circ} \mathrm{C}$.

As shown in Fig. 9, the difference in sample mass between the two reaction paths existed at all four temperatures, but decreased at higher temperatures. This can be explained by the difference in the minimum mass and the final mass between the two sulfation patterns. For example, the sample minimum mass in the simultaneous reaction at $890{ }^{\circ} \mathrm{C}$ was $13.8 \%$ higher than that in the sequential reaction, but at $950{ }^{\circ} \mathrm{C}$ the difference was only $4.2 \%$. The reason for this appears to be that that higher temperatures increase the calcination rate and shorten the time to reach the minimum mass point, which consequently decreased the sulfation ratio at the minimum mass point.

To show the relation more clearly between the differences in the minimum mass and the time to reach the minimum mass point, the mass-loss stages of the two reaction patterns were compared in Fig. 10(a). The calcination ratios and sulfation ratios in the mass-loss stage were also examined to provide more information, in Fig. 10 (b) and (c), respectively.

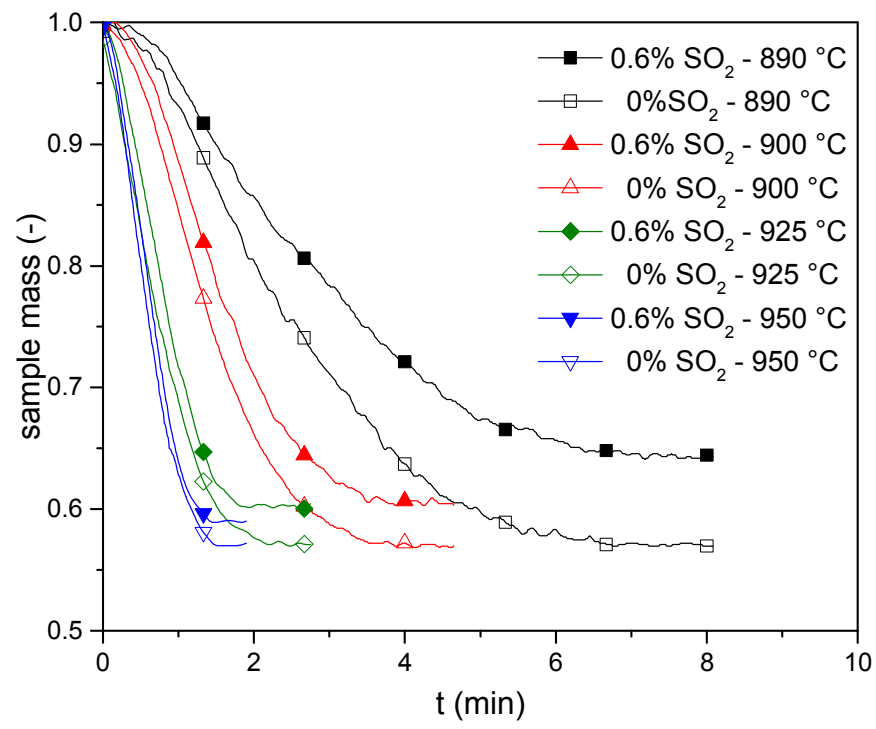

(a) 


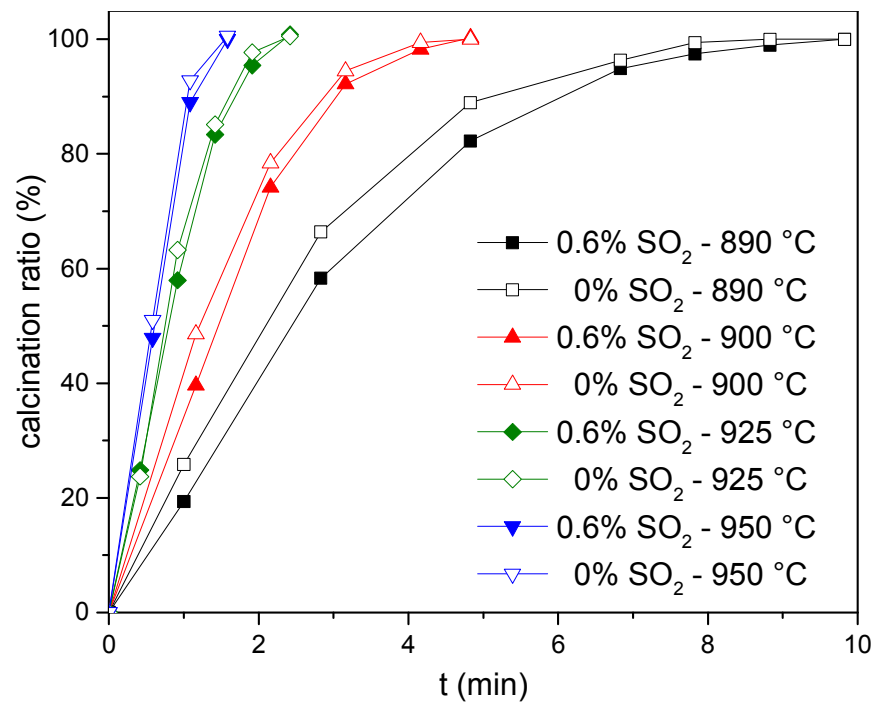

(b)

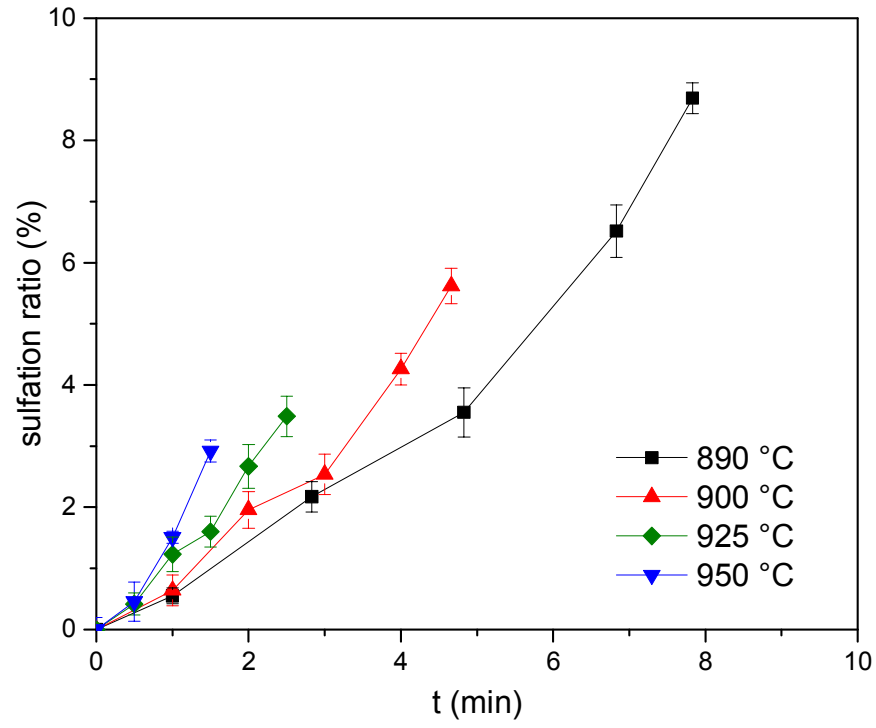

(c)

Fig. 10. The mass-loss stage at different temperatures. (a) the sample mass; (b) the calcination ratio; and (c) the sulfation ratio in the mass-loss stage, under $0.6 \% \mathrm{SO}_{2}$.

In Fig. 10(a), the mass of all samples decreased faster at higher temperatures, and the times to reach the minimum mass point were shorter. Taking the condition with $0.6 \% \mathrm{SO}_{2}$ for example, the time to reach the minimum mass point is $8.2 \mathrm{~min}$ at $890{ }^{\circ} \mathrm{C}$, but only $1.5 \mathrm{~min}$ at $950{ }^{\circ} \mathrm{C}$. The faster mass loss is mainly due to the increased calcination rate at higher temperatures, as is shown clearly in Fig. 10(b).

The difference in the sample minimum mass between the two reaction patterns was smaller at higher temperature (Fig. 10(a)). This is caused mainly by the lower sulfation ratio at the minimum mass point at lower temperatures. As shown in Fig. 10 (c), the sulfation ratio of the minimum mass point at $890{ }^{\circ} \mathrm{C}$ was $8.7 \%$, but only $2.9 \%$ at $950{ }^{\circ} \mathrm{C}$. In Fig. 10 (c), although the sulfation rate was faster at higher temperatures, the time to reach the minimum mass point was much shorter, which resulted in a lower sulfation degree at the minimum mass point at higher temperatures. 
Fig. 10(b) shows that the calcination rate under $0.6 \% \mathrm{SO}_{2}$ was lower than that without $\mathrm{SO}_{2}$ over the entire tested temperature range. This means that the pore filling or blocking by $\mathrm{CaSO}_{4}$ may still occur at temperature as high as $950{ }^{\circ} \mathrm{C}$. To demonstrate the pore occlusion at this temperature, the samples calcined with 0 and $0.6 \% \mathrm{SO}_{2}$ were collected at the minimum mass point $(1.5 \mathrm{~min})$, and their pore structures were analyzed by the $\mathrm{N}_{2}$ adsorption method. The pore surface area and pore volume are shown in Table 4, and the pore size distributions are given in Fig. 11. For comparison, the pore structures at $900{ }^{\circ} \mathrm{C}$ are also shown.

Table 4. Specific surface area and pore volume of samples at different temperatures.

\begin{tabular}{lllll}
\hline Temperature $\left({ }^{\circ} \mathrm{C}\right)$ & Time $(\mathrm{s})$ & $\mathrm{SO}_{2}(\%)$ & surface area $\left(\mathrm{m}^{2} / \mathrm{g}\right)$ & pore volume $\left(\mathrm{cm}^{3} / \mathrm{g}\right)$ \\
\hline 900 & 280 & 0 & 11.27 & 0.1285 \\
900 & 280 & 0.6 & 10.04 & 0.0665 \\
950 & 90 & 0 & 14.34 & 0.1476 \\
950 & 90 & 0.6 & 13.28 & 0.0298 \\
\hline
\end{tabular}

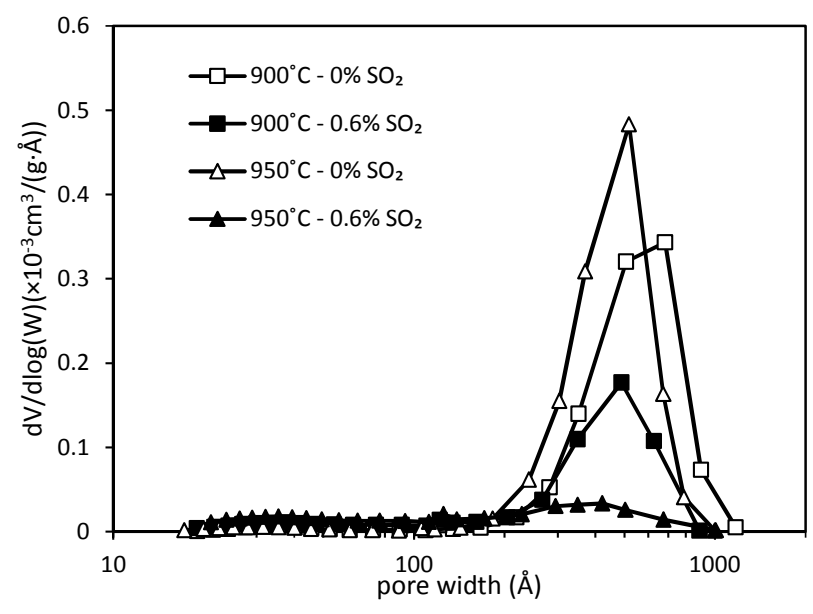

Fig. 11. Pore size distribution of samples under different temperatures.

As shown in Table 4 , at $950{ }^{\circ} \mathrm{C}$ the pore surface area and pore volume in $0.6 \% \mathrm{SO}_{2}$ were $7.4 \%$ and $79.8 \%$ lower, respectively, than those values without $\mathrm{SO}_{2}$, similar to that at $900{ }^{\circ} \mathrm{C}$. In Fig. 11, the peak of the pore size distribution at $0.6 \% \mathrm{SO}_{2}$ was lower compared with that without $\mathrm{SO}_{2}$ at $950{ }^{\circ} \mathrm{C}$. It is obvious that at $950{ }^{\circ} \mathrm{C}$ some pores were filled or blocked by the formed $\mathrm{CaSO}_{4}$ when the samples were calcined in an atmosphere containing $\mathrm{SO}_{2}$, although the calcination stage was much shorter than that at $900{ }^{\circ} \mathrm{C}$.

Thus, over the entire range of $900-950{ }^{\circ} \mathrm{C}$, the pore occlusion caused by sulfation reaction was obvious and strongly influenced the calcination reaction. Combined with the findings in Fig. 9, it can be concluded that in the range of $900-950{ }^{\circ} \mathrm{C}$, both the calcination and sulfation characteristics of the simultaneous reaction are different from those of the sequential reaction. Since the furnace temperature of CFB significantly affects the sulfur capture efficiency, experiments to find the optimum temperature for sulfation should also be carried out on the simultaneous reaction. To better elucidate the influence of temperature on the simultaneous reaction, the sample mass at the four different temperatures were compared in Fig. 12. 


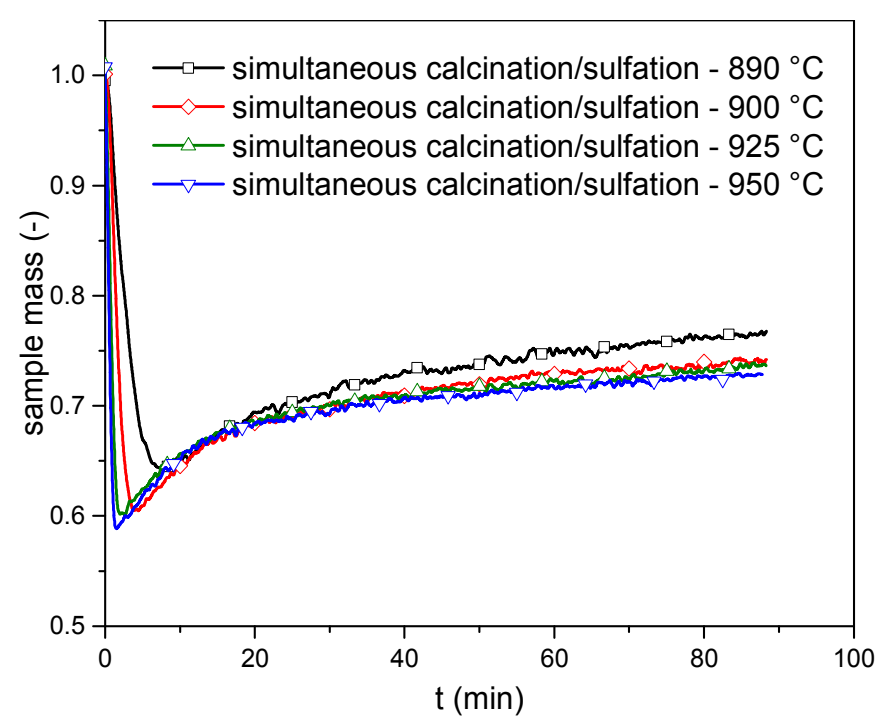

Fig. 12. Effect of temperature on the simultaneous reaction.

As shown in Fig. 12, with the temperature increasing in the range of $890-950{ }^{\circ} \mathrm{C}$, the mass-loss rate increased, the minimum mass point declined and the time to reach it was shorter. The final sample mass at 90 min decreased at higher temperatures. Since the $\mathrm{CaCO}_{3}$ decomposed completely after $10 \mathrm{~min}$ for the four tested temperatures (Fig. 10(b)), the sample mass over this time reflected the sulfation degree of the samples. Therefore, Fig. 12 shows that the sulfation rate in the slow sulfation stage decreased from 890 to $950{ }^{\circ} \mathrm{C}$, and the final sulfation degree also decreased in this temperature range. The final sulfation ratio was not influenced strongly by temperature in range $900-950{ }^{\circ} \mathrm{C}$. It seems that in the range of $890-950{ }^{\circ} \mathrm{C}$, $890{ }^{\circ} \mathrm{C}$ is the optimum temperature to achieve the highest sulfation performance for this limestone.

\subsection{Effect of $\mathrm{H}_{2} \mathrm{O}$ on the simultaneous reaction}

$\mathrm{H}_{2} \mathrm{O}$ is one of the main components of flue gases. It has been found that both the calcination and sulfation reaction can be affected by $\mathrm{H}_{2} \mathrm{O}$ [36]. To study the influence of $\mathrm{H}_{2} \mathrm{O}$ on the simultaneous reaction, Baoding limestone was tested under $0 \%$ or $8 \%$ $\mathrm{H}_{2} \mathrm{O}$ and $0.6 \% \mathrm{SO}_{2}$. The effect of $\mathrm{H}_{2} \mathrm{O}$ on the sequential reaction was also tested for comparison. Fig. 13 shows the mass of the samples under these conditions.

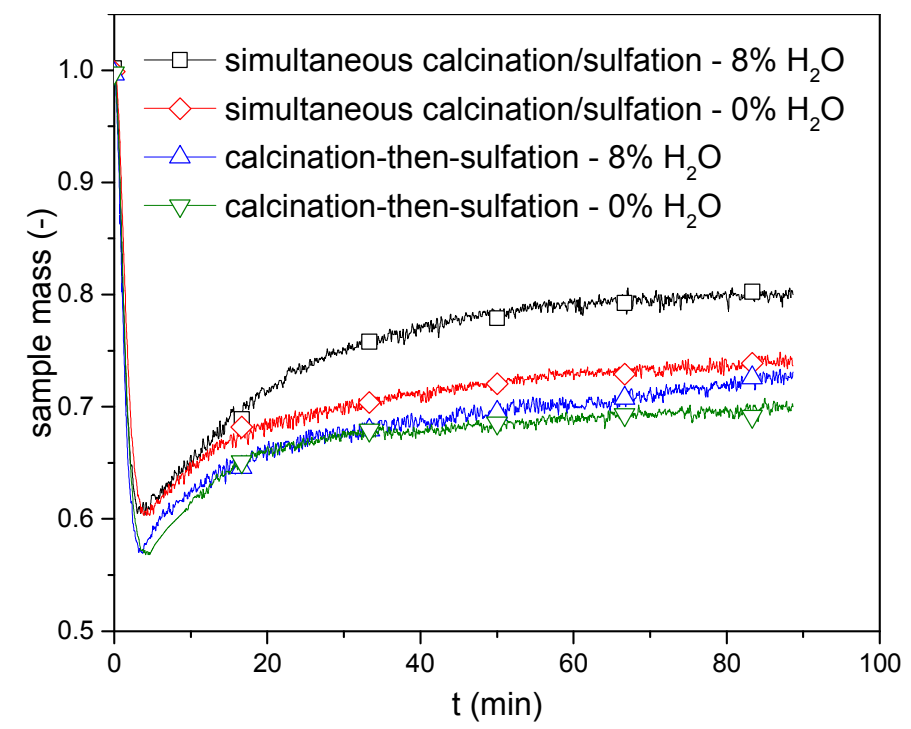


Fig. 13. Effect of $\mathrm{H}_{2} \mathrm{O}$ on the simultaneous reaction and sequential reaction.

The effect of $\mathrm{H}_{2} \mathrm{O}$ on the sulfation of $\mathrm{CaO}$ has been studied by several researchers, and the consensus is that $\mathrm{H}_{2} \mathrm{O}$ can improve the sulfation rate of limestone [19, 21]. A similar phenomenon is shown here. For the sequential reaction in Fig. 13, the reaction rate of the fast sulfation stage with $8 \% \mathrm{H}_{2} \mathrm{O}$ was close to that with $0 \% \mathrm{H}_{2} \mathrm{O}$, but the reaction rate in the slow sulfation stage was improved by $\mathrm{H}_{2} \mathrm{O}$, resulting in $4.3 \%$ increase in the final mass. For the simultaneous reaction, $\mathrm{H}_{2} \mathrm{O}$ also significantly increased the rate of the slow sulfation stage, and improved the final mass by $8.5 \%$. It seems that the effect of $8 \% \mathrm{H}_{2} \mathrm{O}$ is more pronounced on the simultaneous reaction than on the sequential reaction.

To better understand the effect of $\mathrm{H}_{2} \mathrm{O}$ on the calcination reaction, the mass-loss stage in Fig. 13 is shown in Fig. 14(a) in greater detail. The calcination ratio under each condition was measured, in Fig. 14(b).

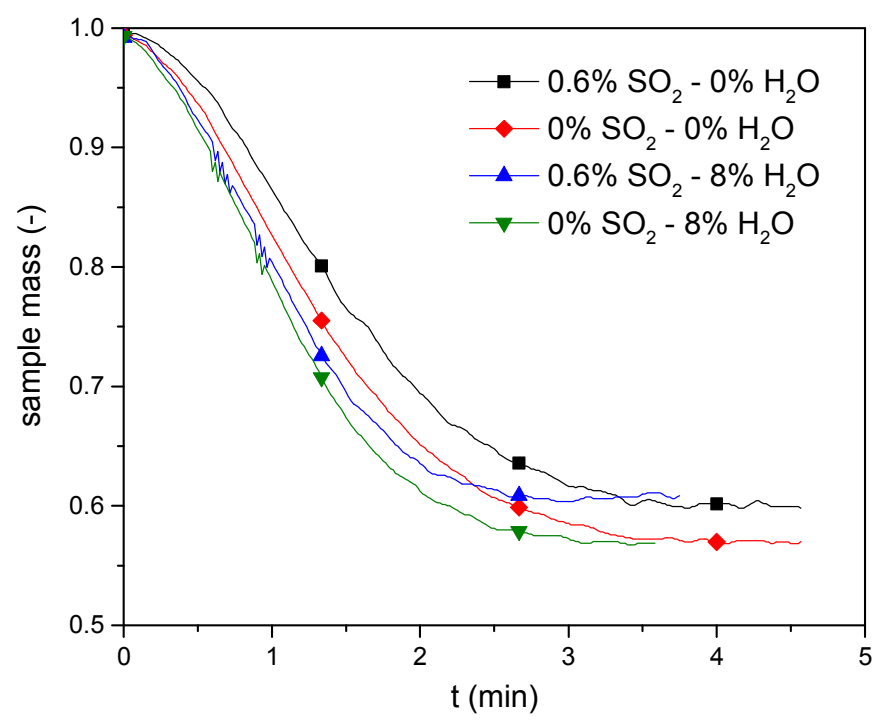

(a)

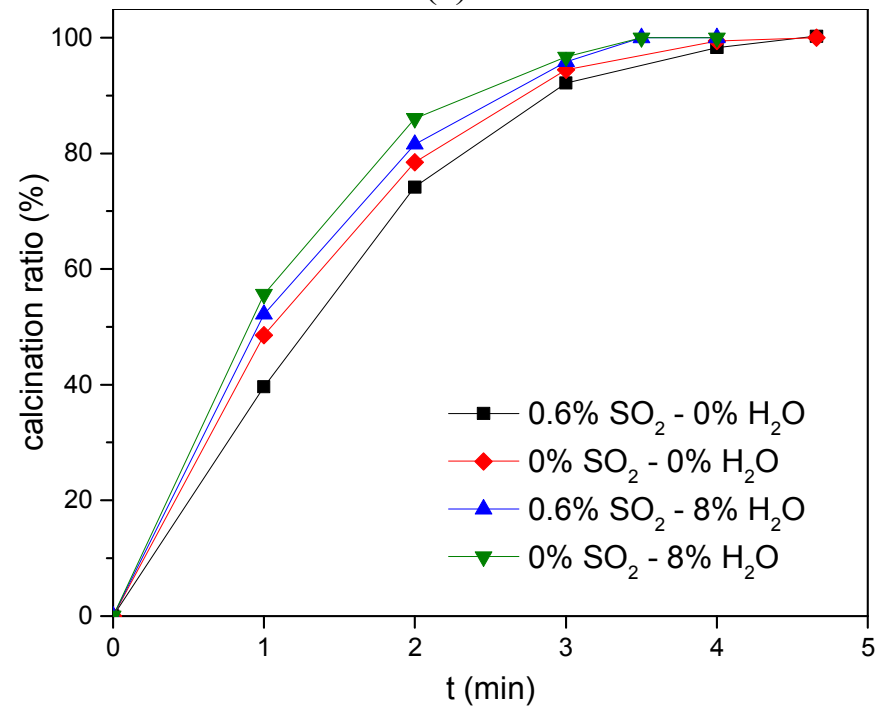

(b)

Fig. 14. The mass-loss stage at different temperatures with/without $\mathrm{SO}_{2}$ and $\mathrm{H}_{2} \mathrm{O}$. (a) 
the sample mass; (b) the calcination ratio.

As shown in Fig. 14(a), the mass-loss rate in both reaction modes was improved by the $8 \% \mathrm{H}_{2} \mathrm{O}$, and the times to reach the minimum mass point were shorter. For example with $0.6 \% \mathrm{SO}_{2}$, the time to reach the minimum mass point (2.92 min) under $8 \% \mathrm{H}_{2} \mathrm{O}$ was about 0.83 min less than that (3.75 min) under $0 \% \mathrm{H}_{2} \mathrm{O}$. The faster mass loss rate under $8 \% \mathrm{H}_{2} \mathrm{O}$ must be mainly due to the increased calcination rate. As demonstrated in Fig. 14(b), the calcination rates under $0 \%$ or $0.6 \% \mathrm{SO}_{2}$ were both increased in $8 \% \mathrm{H}_{2} \mathrm{O}$.

From Fig. 14(b), it can be seen that under all four conditions the samples were calcined completely at $4.7 \mathrm{~min}$. Therefore, the sulfation ratio of the final sample can be calculated directly from the sample mass of Fig. 13. Under conditions without $\mathrm{H}_{2} \mathrm{O}$, the sulfation ratio of calcium in the simultaneous reaction was $26.6 \%$ higher than that in the sequential reaction. But under conditions with $8 \% \mathrm{H}_{2} \mathrm{O}$, the difference in sulfation ratio between the two modes was $42.7 \%$, and was much larger than that without $\mathrm{H}_{2} \mathrm{O}$.

In oxy-fuel CFB boilers, the flue gases contain about $10 \% \mathrm{H}_{2} \mathrm{O}$ (in dry flue gas recycle) or even higher (in wet flue gas recycle). In this case, the difference between the simultaneous and sequential reaction would be correspondingly greater. Therefore, taking the sulfation of $\mathrm{CaO}$ as the real reaction process of limestone will introduce significant errors to the sulfation studies in oxy-fuel CFB.

\subsection{Effect of limestone}

To demonstrate that the differences between the simultaneous reaction and the sequential reaction were not limited to only one limestone, another limestone (Xinxiang) was also tested. The tests were under conditions of $0.6 \% \mathrm{SO}_{2}$ and $8 \% \mathrm{H}_{2} \mathrm{O}$ at $900{ }^{\circ} \mathrm{C}$. The sample mass is shown in Fig. 15(a). The mass and the calcination ratio of samples in the mass-loss stage are shown in Fig. 15(b).

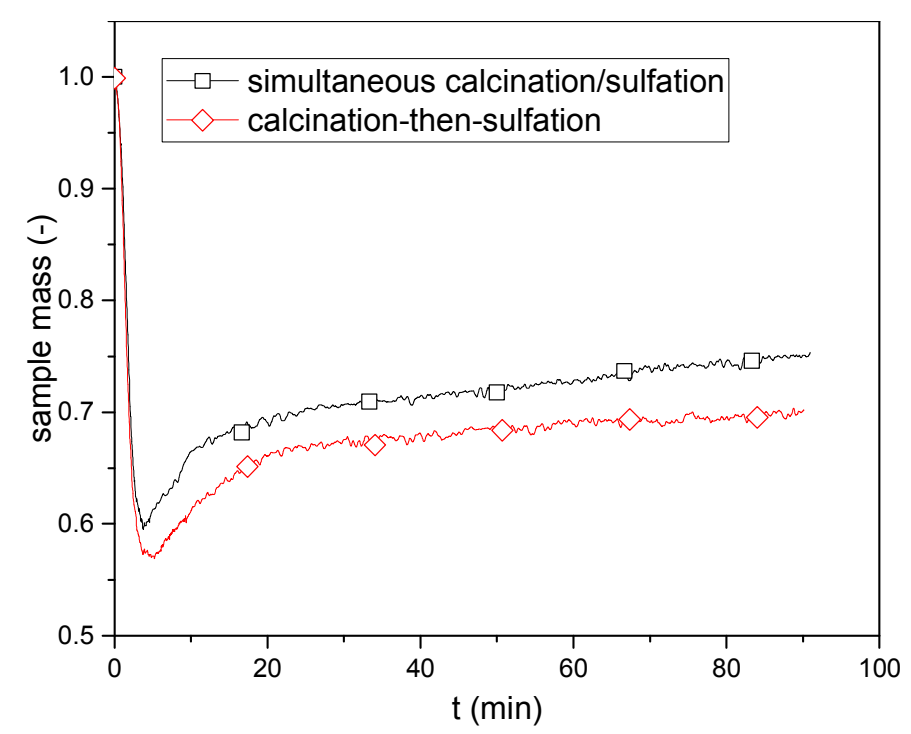

(a) 


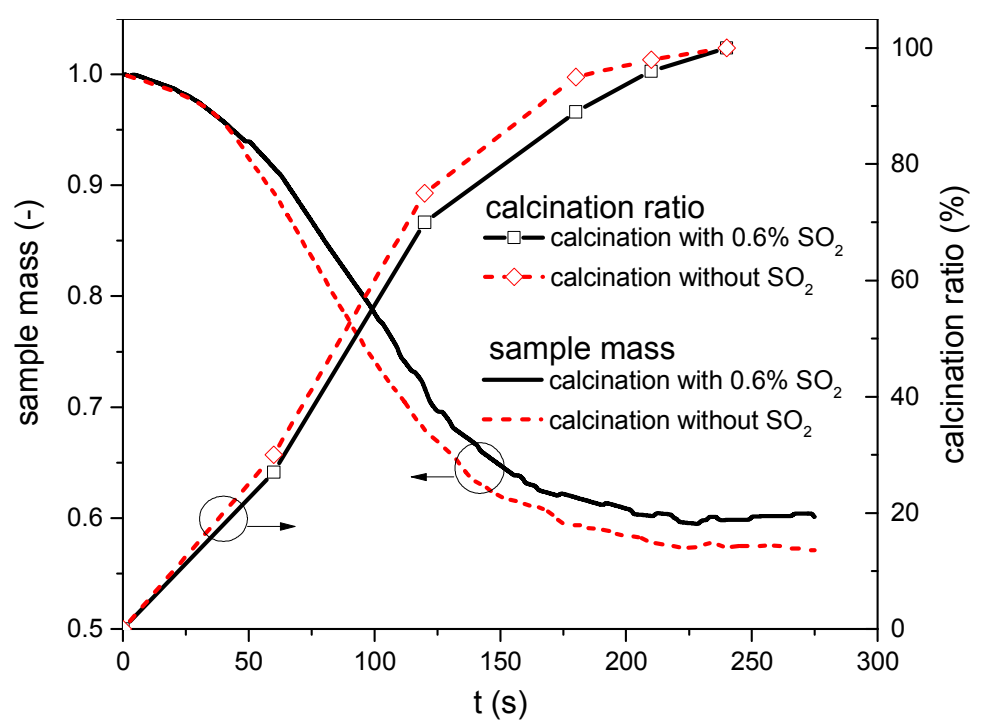

(b)

Fig. 15. The simultaneous reaction and the sequential reaction of Xinxiang limestone. (a) the sample mass; (b) the sample mass and calcination ratio in the mass-loss stage.

As shown in Fig. 15(a), the sample mass of the simultaneous reaction is always larger than that of the sequential reaction. From Fig. 15(b), the mass-loss rate with $0.6 \% \mathrm{SO}_{2}$ was slower than that without $\mathrm{SO}_{2}$, and the calcination rate with $0.6 \% \mathrm{SO}_{2}$ was slower than that without $\mathrm{SO}_{2}$. The final sulfation ratio $(23.1 \%$ ) at $90 \mathrm{~min}$ for simultaneous reaction was $37.5 \%$ larger than that (16.8\%) for the sequential reaction. These phenomena demonstrated with Xinxiang limestone were similar to those observed with Baoding limestone. Therefore, the findings in this work are not limited to only one limestone, and can be considered as general phenomena.

\section{Conclusions}

The differences between the simultaneous calcination/sulfation reaction and the calcination-then-sulfation reaction under oxy-fuel CFB conditions were investigated. The mass of sample in the simultaneous reaction was always higher than that in the sequential reaction for $90 \mathrm{~min}$ reaction. With the increase of $\mathrm{SO}_{2}$ concentration $(0-0.9 \%)$ and the decrease of temperature $\left(890-950{ }^{\circ} \mathrm{C}\right)$, the difference of the sample mass between the two reaction patterns increased. When the reaction atmosphere contained $8 \% \mathrm{H}_{2} \mathrm{O}$, the difference of the sample mass between the two reaction patterns was higher than that without $\mathrm{H}_{2} \mathrm{O}$. The difference of the sample mass at the minimum mass point between the two reaction patterns appears to be due to the slowed calcination reaction and the $\mathrm{CaSO}_{4}$ formed in the mass-loss stage. The $\mathrm{CaSO}_{4}$ decreased the calcination reaction rate by filling or blocking the pores in the $\mathrm{CaO}$ layer and increasing the $\mathrm{CO}_{2}$ diffusion resistance, which has been proven by the pore structure measurement and effectiveness factors. Because of the different reaction characteristics between the two reaction patterns, the investigation on the sulfation of limestone under oxy-fuel CFB conditions should follow the simultaneous reaction, rather than the sequential reaction.

The sulfation ratio in the simultaneous reaction at 90 min increased at higher $\mathrm{SO}_{2}$ 
concentration. In the temperature range examined, $890{ }^{\circ} \mathrm{C}$ was the optimum for the sulfation here. The sulfation ratio of the simultaneous reaction was increased significantly by the presence of $8 \% \mathrm{H}_{2} \mathrm{O}$. In the simultaneous reaction, the sulfation rate in the mass-loss stage was higher than that in the fast sulfation stage, which appears to be due to the continuous generation of nascent $\mathrm{CaO}$ in the mass-loss stage. The test on another limestone also demonstrates that these findings should be considered to represent general phenomena for limestone sulfation.

\section{Acknowledgement}

This work was supported by the National Key R\&D Program of China [2016YFB0600701], and the Fundamental Research Funds for the Central Universities [2018ZD03].

\section{References}

[1] Jia L, Tan Y, Wang C, Anthony EJ. Experimental Study of Oxy-Fuel Combustion and Sulfur Capture in a Mini-CFBC. Energ Fuel 2007; 21(6):3160-3164.

[2] Tan Y, Jia L, Wu Y, Anthony EJ. Experiences and results on a $0.8 \mathrm{MWth}$ oxy-fuel operation pilot-scale circulating fluidized bed. Appl Energ 2012; 92:343-347.

[3] Leckner B, Gómez-Barea A. Oxy-fuel combustion in circulating fluidized bed boilers. Appl Energ 2014; 125:308-318.

[4] Jia L, Tan Y, Anthony EJ. Emissions of $\mathrm{SO}_{2}$ and NOx during Oxy-Fuel CFB Combustion Tests in a Mini-Circulating Fluidized Bed Combustion Reactor. Energ Fuel 2010; 24(2):910-915.

[5] Anthony EJ, Granatstein DL. Sulfation phenomena in fluidized bed combustion systems. Prog Energ Combust 2001; 27(2):215-236.

[6] Baker EH. The Calcium Oxide-Carbon Dioxide System in the Pressure Range 1-300 Atmospheres. Journal of the Chemical Society 1962; 70:464-470.

[7] de Las Obras-Loscertales M, de Diego LF, García-Labiano F, Rufas A, Abad A, Gayán P, et al. Modeling of Limestone Sulfation for Typical Oxy-Fuel Fluidized Bed Combustion Conditions. Energ Fuel 2013; 27(4):2266-2274.

[8] García-Labiano F, Rufas A, de Diego LF, Obras-Loscertales MDL, Gayán P, Abad A, et al. Calcium-based sorbents behaviour during sulphation at oxy-fuel fluidised bed combustion conditions. Fuel 2011; 90(10):3100-3108.

[9] Ghosh-Dastidar A, Mahuli SK, Agnihotri R, Fan L. Investigation of High-Reactivity Calcium Carbonate Sorbent for Enhanced $\mathrm{SO}_{2}$ Capture. Ind Eng Chem Res 1996; 35(2):598-606.

[10] de Diego LF, de Las Obras-Loscertales M, García-Labiano F, Rufas A, Abad A, Gayán P, et al. Characterization of a limestone in a batch fluidized bed reactor for sulfur retention under oxy-fuel operating conditions. Int J Greenh Gas Con 2011; 5(5):1190-1198.

[11] Snow MJH, Longwell JP, Sarofim AF. Direct sulfation of calcium carbonate. Ind Eng Chem Res 1988; 27(2):268-273.

[12] de Diego LF, de Las Obras-Loscertales M, Rufas A, García-Labiano F, Gayán P, Abad A, et al. Pollutant emissions in a bubbling fluidized bed combustor working in oxy-fuel operating conditions: Effect of flue gas recirculation. Appl Energ 2013; 102:860-867.

[13] de Diego LF, Rufas A, García-Labiano F, de Las Obras-Loscertales M, Abad A, Gayán P, et al. 
Optimum temperature for sulphur retention in fluidised beds working under oxy-fuel combustion conditions. Fuel 2013; 114:106-113.

[14] Gómez M, Fernández A, Llavona I, Kuivalainen R. Experiences in sulphur capture in a 30 MWth Circulating Fluidized Bed boiler under oxy-combustion conditions. Appl Therm Eng 2014; 65(1-2):617-622.

[15] Burnham AK, Stubblefield CT, Campbell JH. Effects of gas environment on mineral reactions in Colorado oil shale. Fuel 1980; 59(12):871-877.

[16] Wang C, Zhang Y, Jia L, Tan Y. Effect of water vapor on the pore structure and sulfation of $\mathrm{CaO}$. Fuel 2014; 130:60-65.

[17] Wang Y, Lin S, Suzuki Y. Limestone Calcination with $\mathrm{CO}_{2}$ Capture (II) - Decomposition in $\mathrm{CO}_{2}$-Steam and $\mathrm{CO}_{2}-\mathrm{N}_{2}$ Atmospheres. Energ Fuel 2008; 22(4):2326-2331.

[18] Wang Y, Thomson WJ. The effects of steam and carbon dioxide on calcite decomposition using dynamic X-ray diffraction. Chem Eng Sci 1995; 50(9):1373-1382.

[19] Wang C, Jia L, Tan Y, Anthony EJ. The effect of water on the sulphation of limestone. Fuel 2010; 89(9):2628-2632.

[20] Stewart MC, Manovic V, Anthony EJ, Macchi A. Enhancement of Indirect Sulphation of Limestone by Steam Addition. Environ Sci Technol 2010; 44(22):8781-8786.

[21] Jiang Z, Duan L, Chen X, Zhao C. Effect of Water Vapor on Indirect Sulfation during Oxy-fuel Combustion. Energ Fuel 2013; 27(3):1506-1512.

[22] de Las Obras-Loscertales M, Rufas A, de Diego LF, García-Labiano F, Gayán P, Abad A, et al. Morphological analysis of sulfated Ca-based sorbents under conditions corresponding to oxy-fuel fluidized bed combustion. Fuel 2015; 162:264-270.

[23] Takkinen S, Hyppänen T, Saastamoinen J, Pikkarainen T. Experimental and Modeling Study of Sulfur Capture by Limestone in Selected Conditions of Air-Fired and Oxy-fuel Circulating Fluidized-Bed Boilers. Energ Fuel 2011; 25(7):2968-2979.

[24] Rahiala S, Hyppänen T, Pikkarainen T. Bench-Scale and Modeling Study of Sulfur Capture by Limestone in Typical $\mathrm{CO}_{2}$ Concentrations and Temperatures of Fluidized-Bed Air and Oxy-fuel Combustion. Energ Fuel 2013; 27(12):7664-7672.

[25] Rahiala S, Myöhänen K, Hyppänen T. Modeling the behavior of limestone particles in oxy-fuel CFB processes. Fuel 2014; 127:141-150.

[26] Chen L, Wang C, Wang Z, Anthony EJ. The kinetics and pore structure of sorbents during the simultaneous calcination/sulfation of limestone in CFB. Fuel 2017; 208:203-213.

[27] Wang C, Chen L, Jia L, Tan Y. Simultaneous calcination and sulfation of limestone in CFBB. Appl Energ 2015; 155:478-484.

[28] Olas M, Kobyłecki R, Bis Z. Simultaneous calcination and sulfation of limestone-based sorbents in CFBC - Effect of mechanical activation. Proceedings of the 9th international conference on circulating fluidized beds, in conjunction with the 4th international VGB workshop "operating experience with fluidized bed firing systems". Hamburg, Germany 2008.

[29] Chen C, Zhao C. Mechanism of Highly Efficient In-Furnace Desulfurization by Limestone under $\mathrm{O}_{2} / \mathrm{CO}_{2}$ Coal Combustion Atmosphere. Ind Eng Chem Res 2006; 45(14):5078-5085.

[30] Wang C, Chen L. The effect of steam on simultaneous calcination and sulfation of limestone in CFBB. Fuel 2016; 175:164-171.

[31] Hu G, Dam-Johansen K, Wedel S, Peterhansen J. Review of the direct sulfation reaction of limestone. Prog Energ Combust 2006; 32(4):386-407. 
[32] Wang C, Zhou X, Jia L, Tan Y. Sintering of Limestone in Calcination/Carbonation Cycles. Ind Eng Chem Res 2014; 53(42):16235-16244.

[33] Fogler HS. Elements of Chemical Reaction Engineering. 4th ed. New York: Prentice Hall PTR; 2006.

[34] García-Labiano F, Abad A, De Diego LF, Gayán P, Adánez J. Calcination of calcium-based sorbents at pressure in a broad range of $\mathrm{CO}_{2}$ concentrations. Chem Eng Sci 2002; 57(13):2381-2393.

[35] Fuller EN, Schettler PD, Giddings JC. New Method for Predition of Binary Gas-phase Diffusion Coefficients. Industrial \& Engineering Chemistry 1966; 58(5):18-27.

[36] Wang H, Guo S, Liu D, Guo Y, Gao D, Sun S. A Dynamic Study on the Impacts of Water Vapor and Impurities on Limestone Calcination and $\mathrm{CaO}$ Sulfurization Processes in a Microfluidized Bed Reactor Analyzer. Energ Fuel 2016; 30(6):4625-4634. 


\section{Supporting information}

\section{Accuracy of the experimental system}

\subsection{The baseline}

When the empty sample pan (quartz boat) reached the hot furnace, its weight measured by the weight monitor will suddenly rise, then decrease gradually, at last remain around a value different from that in the ambient temperature, as shown in Fig. S1.

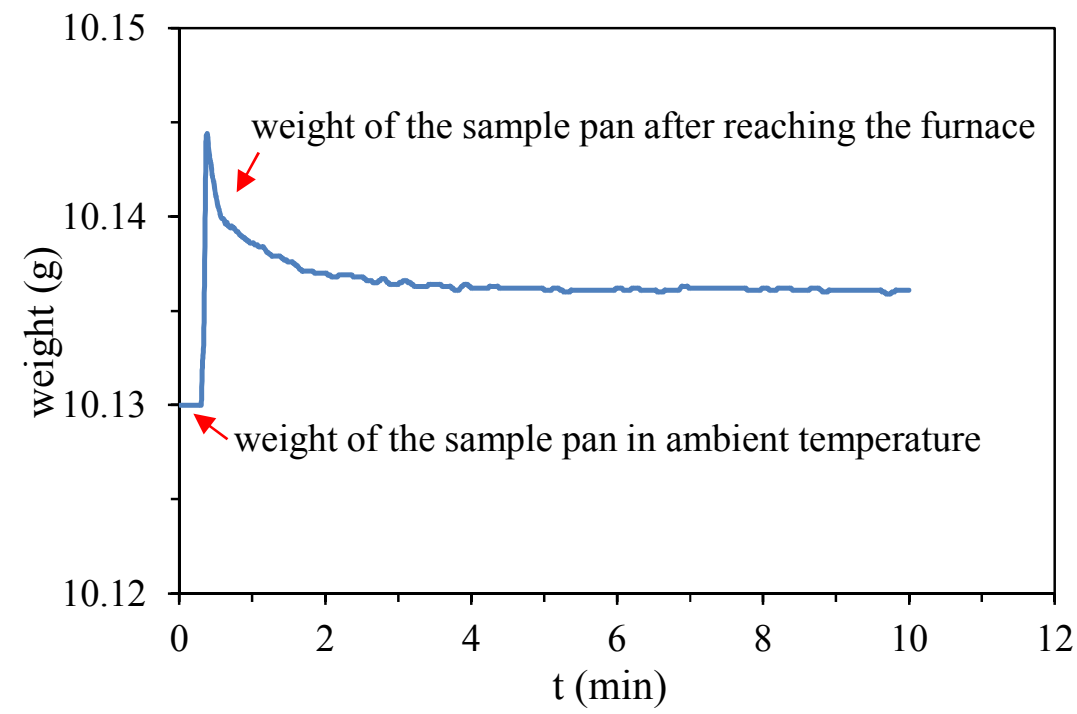

Fig. S1. Mass change after the empty sample pan reached the hot furnace

This phenomenon is due to the difference between the densities of the ambient air and the hot gas in furnace. It will cause error in the weight measured of the sample in experiments. So two sets of weight data were recorded in the tests, the weight of the sample pan with samples (the original line), and the weight of the sample pan without samples (the baseline) under the same reaction condition. The accurate weight of the sample in furnace was obtained by the subtracting the baseline from the original line. Since the baseline varied under different furnace temperatures and gas compositions, a set of baselines were recorded, and the particular baseline was used under each condition.

\subsection{Accuracy of the experimental system}

To validate the accuracy of the experimental system, the stability of the system and the repeatability of tests were examined.

First, the stability of the experimental system was tested. A limestone sample $(0.08 \mathrm{~g}$, particle size 0.4-0.45 mm) was heated at $900{ }^{\circ} \mathrm{C}$ under $70 \% \mathrm{CO}_{2}+30 \% \mathrm{~N}_{2}$ condition. After it was calcined completely, its mass should become about $0.0456 \mathrm{~g}$ (including impurities). Then its weight was recorded continuously for $90 \mathrm{~min}$. After being subtracted by the baseline, the sample mass was shown in Fig. S2. 


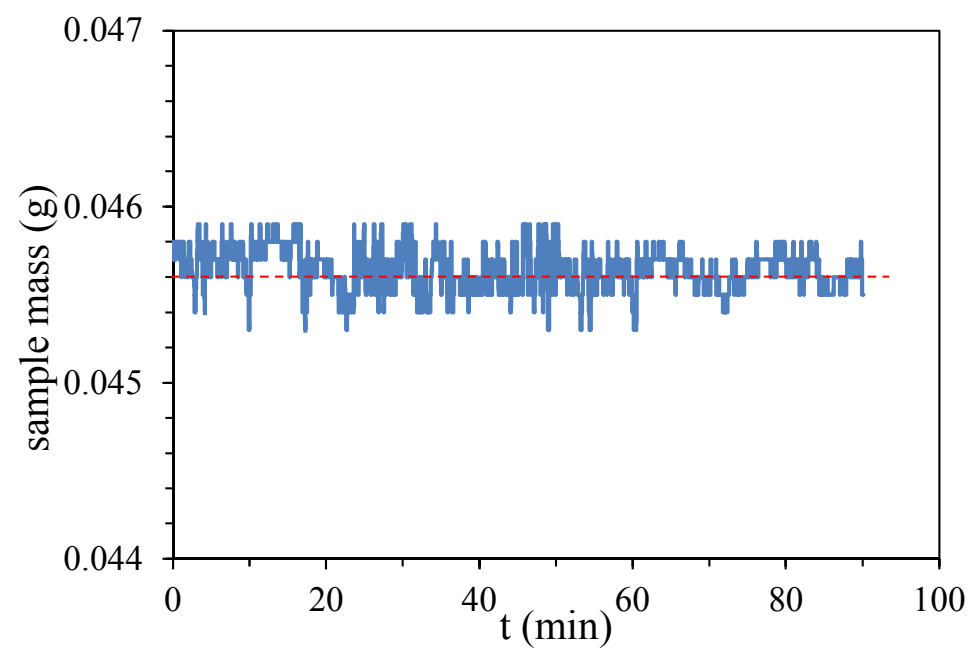

Fig. S2. Sample mass recorded at $900{ }^{\circ} \mathrm{C}$

From Fig. S2, it can be seen that the recorded mass data swings around its actual value $(0.0456 \mathrm{~g}$, shown by the dash line), and the fluctuation was in the range of $\pm 0.0003 \mathrm{~g}$, which corresponding to $\pm 0.7 \%$ of the actual value, so the fluctuation is negligible. Under other temperatures and gas conditions, the same amplitude of fluctuation were seen. So the experimental system is stable under continuous operation.

To examine the repeatability of the system, the $0.4-0.45 \mathrm{~mm}$ limestone particles was calcined at $900{ }^{\circ} \mathrm{C}$ under $70 \% \mathrm{CO}_{2}+30 \% \mathrm{~N}_{2}$ condition. The tests were repeated for three times, the sample mass data were shown in Fig. S3.

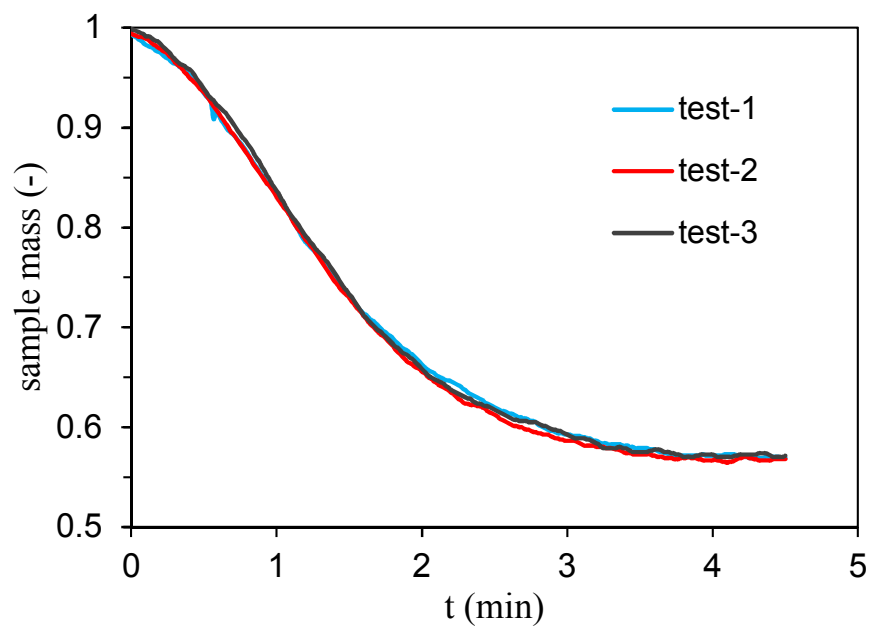

Fig. S3. Sample mass data recorded at $900{ }^{\circ} \mathrm{C}$ under $70 \% \mathrm{CO}_{2}+30 \% \mathrm{~N}_{2}$ condition.

From Fig. S3, it can be seen that the sample mass lines for the three tests under the same conditions almost overlapped, so the repeatability of tests with the system is good enough for this type of experimental work.

\section{Elimination of the external gas diffusion resistance}


To obtain the minimum flow rate of flue gas that can eliminate the external gas diffusion resistance of the calcination reaction, a series of flow rate were tested $(0.3,0.6,0.9,1.2,1.5$ $\mathrm{dm}^{3} / \mathrm{min}$ ). In the testes, $0.4-0.45 \mathrm{~mm}$ limestone particle was used, and the tests were at $950{ }^{\circ} \mathrm{C}$ under $70 \% \mathrm{CO}_{2}+30 \% \mathrm{~N}_{2}$ condition. The results were shown in Fig. S4.

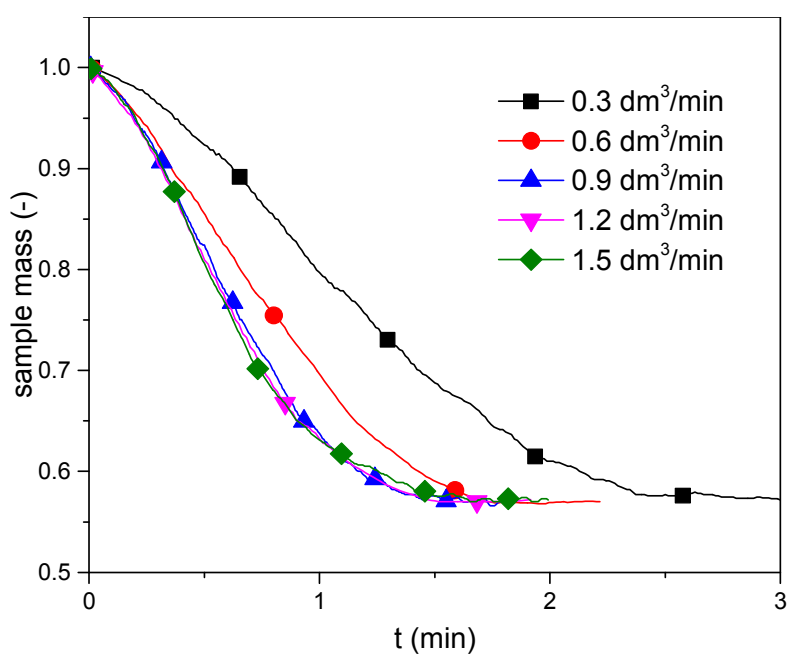

Fig. S4. Calcination process under different flow rate of flue gas.

From Fig. S4, the calcination rate increased with the flow rate in the range of $0.3-0.9 \mathrm{dm} / \mathrm{min}$, while in the range larger than $0.9 \mathrm{dm}^{3} / \mathrm{min}$, the increase of the flow rate did not influence the calcination rate anymore. So the flow rate of $0.9 \mathrm{dm}^{3} / \mathrm{min}$ is the minimum flow rate that can eliminate the external gas diffusion resistance of the calcination reaction.

To determine the minimum flow rate that can eliminate the external gas diffusion resistance of the sulfation reaction, the sulfation process with three flow rates $\left(0.9,1.2,1.5 \mathrm{dm}^{3} / \mathrm{min}\right)$ that are higher than $0.9 \mathrm{dm}^{3} / \mathrm{min}$ were tested (with $0.4-0.45 \mathrm{~mm} \mathrm{CaO}$, at $900{ }^{\circ} \mathrm{C}$, under $0.6 \% \mathrm{SO}_{2}$ condition). The sulfation ratios under different flow rates were shown in Fig. S5.

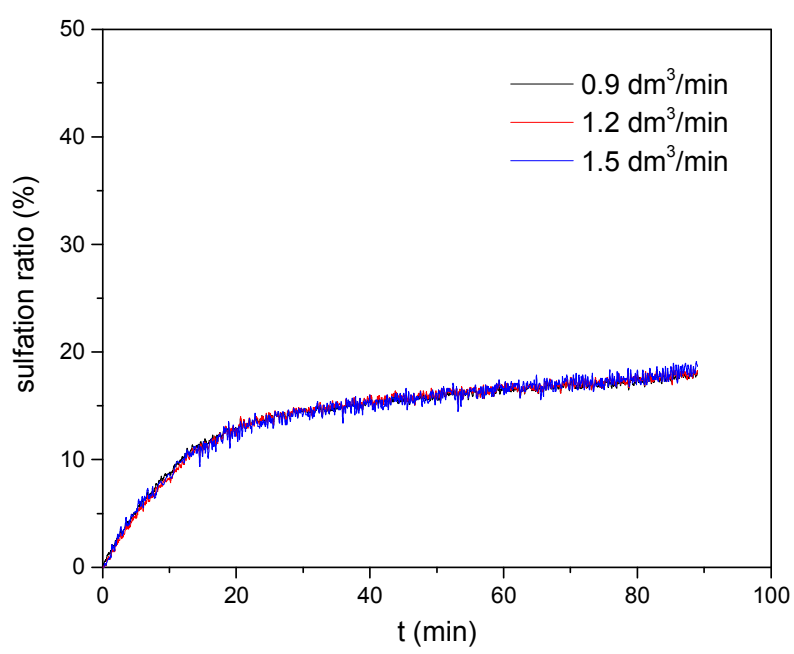

Fig. S5. Sulfation process under different flow rate of flue gas.

From Fig. S5, the sulfation process under the tested three flow rates were almost the same, which means that the flow rates higher than $0.9 \mathrm{dm}^{3} / \mathrm{min}$ are also high enough to eliminate the external gas diffusion resistance of the sulfation reaction under typical conditions. 
Based on the above results, the flow rate of $1.2 \mathrm{dm}^{3} / \mathrm{min}$ was used in all the tests in this work. This flow rate is high enough to eliminate the external gas diffusion resistance of both the calcination and sulfation reaction under typical conditions.

\section{Recarbonation of the sample in the cooling process}

The tube furnace of the experimental system was placed on the guide rail, thus it can be moved horizontally, and the sample pan (quartz boat) loaded with sample can be moved out quickly from the furnace. After being moved from the furnace, the quartz boat as well as the sample was cooled in a glass tube purged by pure $\mathrm{N}_{2}$, as shown in Fig. S6.

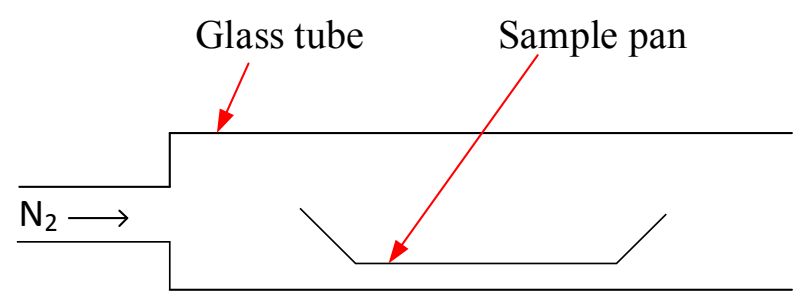

Fig. S6. The glass tube purged by pure $\mathrm{N}_{2}$ to cool the sample

Typically the whole process of moving the sample pan from the furnace to the glass tube takes less than 3 seconds. Thus when the sample reached the glass tube, its temperature decrease is small. On reaching the tube from $900{ }^{\circ} \mathrm{C}$ furnace, the temperature of the sample pan was about $700{ }^{\circ} \mathrm{C}$ (measured by an infrared thermometer), which is higher than the equilibrium temperature for $\mathrm{CaO}$ carbonation in air (about $600^{\circ} \mathrm{C}$ ), thus recarbonation cannot occur.

To further test if there was recarbonation in the moving and cooling process, a completely calcined $\mathrm{CaO}$ sample was used. The $\mathrm{CaO}$ sample was first heated at $900{ }^{\circ} \mathrm{C}\left(70 \% \mathrm{CO}_{2}+30 \% \mathrm{~N}_{2}\right)$, then it was moved into the glass tube, cooled down and weighed. Afterwards, it was re-calcined in pure $\mathrm{N}_{2}$ at $900{ }^{\circ} \mathrm{C}$, and no further mass loss was found. This means that in the moving and cooling process, neither $\mathrm{CO}_{2}$ or $\mathrm{H}_{2} \mathrm{O}$ were absorbed by the $\mathrm{CaO}$ sample. 